Martínez García, Rafael. Museos etnográficos y territorio en el Bajo Segura. GeoGraphos [En línea]. Alicante: Grupo Interdisciplinario de Estudios Críticos y de América Latina (GIECRYAL) de la Universidad de Alicante, 2 de julio de 2020, vol. 11, no 128 p. 158191 [ISSN: 2173-1276] [DL: A 371-2013] [DOI: 10.14198/GEOGRA2020.11.128].

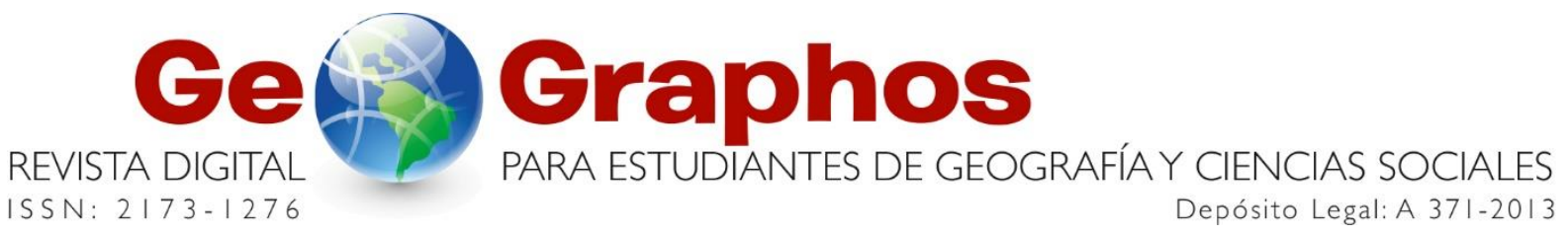

$<\underline{\text { http://web.ua.es/revista-geographos-giecryal }>}$

Vol. 11. N $\mathrm{N}^{\mathrm{o}} 128$

Año 2020

\title{
MUSEOS ETNOGRÁFICOS Y TERRITORIO EN EL BAJO SEGURA ${ }^{1}$
}

\author{
Rafael Martínez García \\ Museo Escolar de Puçol (Elche, España) \\ Correo electrónico: rafaelmartinezgarcia1967@gmail.com
}

Recibido: 28 de abril de 2020. Aceptado: 02 de julio de 2020.

${ }^{1}$ El presente trabajo está basado en la tesis doctoral del autor, titulada Museos etnológicos del sur valenciano. Territorio, identidad y patrimonio, dirigida por el profesor Dr. D. Gregorio Canales, Catedrático de Geografía Humana de la Universidad de Alicante. Véase: Repositorio Institucional de la Universidad de Alicante. [En línea].< http://rua.ua.es/dspace/handle/10045/77432>. [21 de abril de 2020]. 


\title{
RESUMEN
}

En las últimas décadas, en el contexto de los cambios socioeconómicos acaecidos en la comarca del Bajo Segura (Alicante), donde el sector de los servicios - sobre todo aquellos relacionados con el ocio y el turismo - ha pasado a ocupar un papel decisivo, han surgido numerosos museos en la zona, entre otros, de carácter etnográfico. Asimismo, se han puesto en marcha rutas urbanas y rurales, todas ellas iniciativas que interesan al patrimonio y al territorio, fenómeno no exclusivo de nuestra área de estudio. Estos museos etnográficos surgen con el fin de conservar y exhibir la historia y la memoria de su entorno, cuya identidad pretenden mostrar. En el actual escenario global, consideramos que en el Bajo Segura se ha producido una evolución común a otros lugares, en los que se ha pasado de despreciar "lo antiguo" (sus tradiciones, su folklore...), en un primer momento, a comenzar a valorarlo, más tarde, reconociendo su carácter patrimonial, hecho que les ha llevado, en nuestros días, a considerar su pasado reciente como un recurso a potenciar. No obstante, consideramos que los museos etnográficos surgidos en la comarca adolecen de importantes carencias, que condicionan su discurso y su proyección social.

Palabras clave: museo, etnografía, territorio, patrimonio, identidad.

\section{ETHNOGRAPHIC MUSEUMS AND TERRITORY IN THE BAJO SEGURA}

\begin{abstract}
In the last decades, in the context of the socioeconomic changes become in the region of the Bajo Segura (Alicante), where the sector of the services - especially those related with the leisure and the tourism - has happened to occupy a decisive paper, have arisen numerous museums in the zone, amongst other, of ethnographic character. Likewise, they have set up urban and rural routes, all they initiatives that interest to the heritage and to the territory, phenomenon no exclusive of our area of study. These ethnographic museums arise with the end to conserve and exhibit the history and the memory of his surroundings, whose identity pretend to show. In the current global stage, consider that in the Low Safe has produced a common evolution to other places, in which it has happened to despise "the ancient" (his traditions, his folklore...), in a first moment, to begin to value it, later, recognising his character patrimonial, fact that has carried them, in our days, to consider his recent past like a resource to improve. Nevertheless, we consider that the ethnographic museums arisen in the region suffer from of important lacks, that condition his speech and his social projection.
\end{abstract}

Keywords: museum, ethnography, territory, heritage, identity.

\section{MUSEUS ETNOGRÁFICOS E TERRITÓRIO NO BAIXO SEGURA}

\section{RESUMO}

Nas últimas décadas, no contexto das mudanças socioeconómicas acaecidos na comarca do Baixo Segura (Alicante), onde o sector dos serviços - sobretudo aqueles relacionados com o lazer e o turismo - tem passado a ocupar um papel decisivo, têm surgido numerosos museus na zona, entre outros, de carácter etnográfico. Assim mesmo, puseram-se em marcha rotas urbanas e rurais, todas elas iniciativas que interessam ao património e ao território, fenómeno não exclusivo de nossa área de estudo. Estes museus etnográficos surgem com o fim de conservar e exibir a história e a memória de seu meio, cuja 
identidade pretendem mostrar. No actual palco global, consideramos que no Baixo Segura se produziu uma evolução comum a outros lugares, nos que se passou de desprezar "o antigo" (suas tradições, sua folklore...), num primeiro momento, a começar ao valorizar, mais tarde, reconhecendo seu carácter patrimonial, facto que lhes levou, em nossos dias, a considerar seu passado recente como um recurso a potenciar. Não obstante, consideramos que os museus etnográficos surgidos na comarca adolecen de importantes carências, que condicionam seu discurso e sua projecção social.

Palavras-chave: museu, etnografía, território, património, identidade.

\section{INTRODUCCIÓN}

En las últimas décadas hemos asistido a importantes transformaciones en la sociedad y en la economía mundiales. Según la terminología acuñada por Bauman ${ }^{2}$, se ha pasado de un mundo "sólido" a uno "líquido", en el que prima el individuo, lo fugaz, la apariencia, la notoriedad, lo inmediato, lo veloz..., corolario de unos cambios que, de manera general, caracterizan a una (post) moderna sociedad de consumo progresivamente globalizada. Junto al hecho "global" también encontramos "lo local", "el lugar", espacios donde confluyen lo general y lo específico, generando una identidad esgrimida en ocasiones como necesaria para contener la avalancha uniformizadora del postmodernismo. Pese a su desigual impronta en el territorio, la universalización y homogeneidad de comportamientos y saberes transforma "los lugares", que ven amenazada su unicidad ${ }^{3}$. Este contexto así esbozado resulta pródigo en el auge de las identidades, definidas "exclusivamente por su distinción con respecto a todas las demás"; identidad experimentada como producto cultural atemporal e inerte, convertido en arma de autoafirmación capaz de otorgar seguridad ${ }^{4}$.

El presente trabajo se aproxima de manera indirecta al estudio del fenómeno identitario, y lo hace a partir del análisis de un producto social específico, como es el museo: en concreto, el museo etnográfico, aquel que explica el "etno", entendido como pueblo, como aquello "local". En las líneas que siguen, por tanto, se aborda el estudio de esta tipología de museos existente en un territorio o "lugar", aquellos que conforman unos espacios que se erigen en depositarios de su identidad y como reserva de aquello que permanece y lo caracteriza. Este es un estudio de geografía considerada "clásica", cuando menos en un doble sentido: en primer lugar, porque se circunscribe a un territorio específico, la comarca del Bajo Segura (Alicante), la más meridional de la Comunidad Valenciana (figuras 1 y 2). Y, en segundo término, porque se aproxima al componente territorial presente en estos museos. Expliquemos ambos puntos.

${ }^{2}$ BAUMAN, Z. Vida líquida. Barcelona: Ediciones Paidós, 2019. 206 p.

${ }^{3}$ NOGUÉ, J. Cartografía de los cambios sociales y culturales. En ROMERO, J. Geografía Humana. $2^{\mathrm{a}}$ ed. Barcelona: Editorial Ariel, 2007, p. 173-219.

${ }^{4}$ BAUMAN, Z., op.cit., p. 47-48.

${ }^{5}$ Real Academia Española. [En línea]. <https://dle.rae.es/etno->. [1 de abril de 2020]. 


\section{Figura 1. La Península Ibérica y la Comunidad Valenciana.}
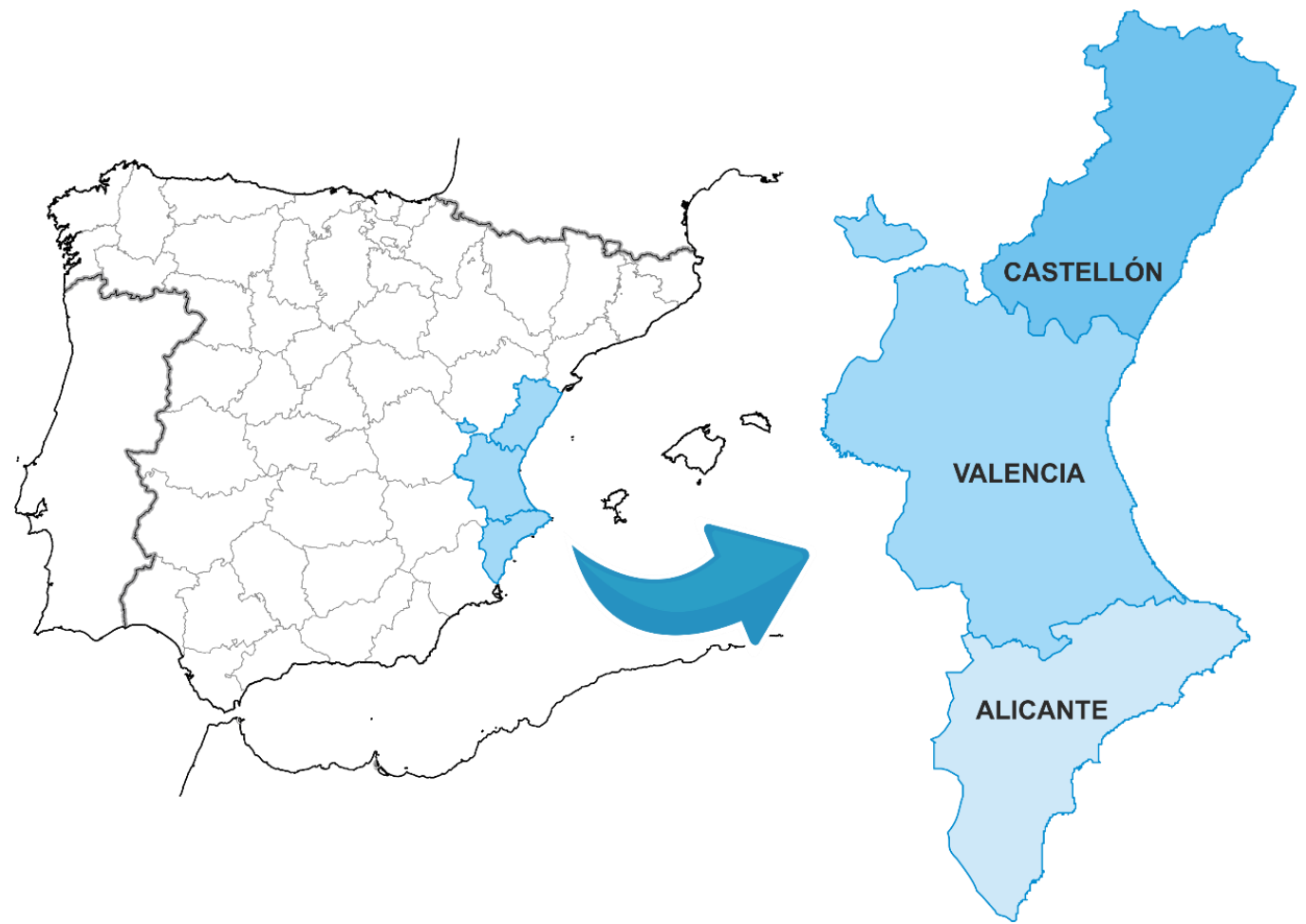

Fuente: Elaboración propia.

¿Por qué el Bajo Segura? La Vega Baja - como también se la conoce popularmente -, territorio esencialmente agrícola hasta el último tercio del siglo XX, en la actualidad se halla inmerso en una coyuntura de cambio. Un espacio cercano a los $1.000 \mathrm{~km}^{2}$, hasta hace unas décadas de dilatados paisajes de campo y huerta en torno al río Segura, se ha visto profundamente alterado en los últimos años. Integrada en una economía avanzada, la comarca no ha sido ajena a los profundos cambios mundiales, a los que se ha incorporado con fuerza. Los servicios han irrumpido en un territorio que se ha volcado en la construcción y el turismo, experimentando trascendentales mutaciones en un corto espacio de tiempo.

Junto a ello, la degradación imparable del entorno ha originado que hayan surgido voces en su defensa (colectivo Pro-Río en la defensa del Segura o la Plataforma Anticorrupción Defensa de la Huerta, entre otros), testimonios y protagonistas que buscan concienciar a la sociedad. Cuando el proceso de cambio ha culminado y esta se ha modernizado es cuando se asiste a una suerte de reacción, cuando se es consciente del espacio/tiempo que se acaba de atravesar y de lo que se ha dejado atrás, que se comienza a valorar ${ }^{6}$. En esta fase, que hemos bautizado como "de reacción" - no exclusiva de nuestro territorio, sino que resulta común a otros espacios y sociedades de similar trayectoria -, es en la que, en nuestra opinión, se encuentra inmerso el Bajo Segura. Y es en este contexto en el que hay que situar la creación de museos etnográficos en la comarca, espacios para la nostalgia y la memoria que nos hablan de un pasado idílico en el que aún existía un río, una tierra y unas gentes "auténticas". Estudiar estos museos y conocer también cómo interpretan el territorio en el que surgen - cómo se ven a sí mismos y cómo ven "su casa" - es la segunda de estas cuestiones geográficas que consideramos necesario abordar.

${ }^{6}$ GREGORI, J. Per què uns museus d'etnologia en l'entorn alacantí? Canelobre. Revista del Instituto Alicantino de Cultura «Juan Gil-Albert», 2000, n 41/42, p. 97-116. 
Figura 2. Comunidad Valenciana y división comarcal de la provincia de Alicante

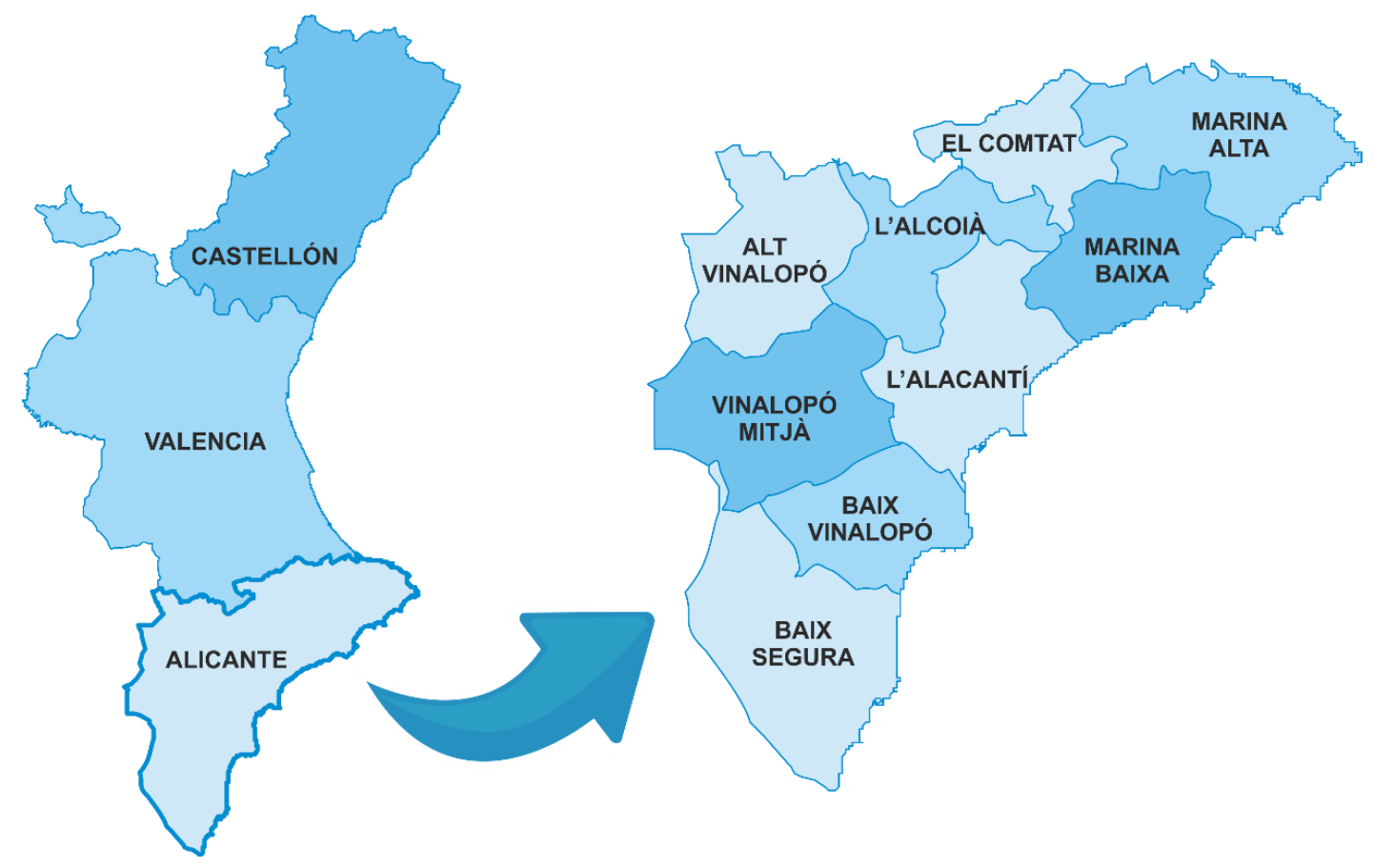

Fuente: elaboración propia.

El cuadro 1 muestra los museos, colecciones museográficas y otros espacios etnográficos existentes en el Bajo Segura, susceptibles de explicar la cultura de su entorno. El cuadro recoge un total de quince espacios ${ }^{7}$, nueve de los cuales - el $60 \%$ - han surgido en el presente siglo; de esos quince espacios, solo seis - el $40 \%$ - están reconocidos como museos o colecciones museográficas. Como se puede observar, el cuadro incluye el centro de visitantes del único parque natural de la comarca y un molino hidráulico, espacios que, a pesar de no ser considerados ni museos ni colecciones museográficas, son públicos, exponen piezas y, a partir de ellas, elaboran un discurso sobre su historia y su medio; y, en la medida en que realizan estas funciones, difunden un mensaje sobre sí mismos que consideramos relevante incluir en el presente trabajo.

Y, a propósito del mensaje subyacente en estos espacios, son muchas las preguntas que cabe plantearse al abordar este análisis: ¿Cuál es su discurso? ¿En qué se basan? ¿Reflejan "fielmente" su entorno? Estas son solo algunas cuestiones que nos hacemos al inicio de este artículo y a las que intentaremos responder a lo largo de sus páginas, elaborando una

\footnotetext{
${ }^{7}$ No se incluyen dos espacios que ya cerraron sus puertas, como, en primer lugar, el museo etnológico de Desamparados - creado en 1985 como museo filial del arqueológico comarcal de Orihuela, gracias al empuje de una asociación local -, situado en la escuela de la pedanía homónima. ADAMACO. Asociación de Amigos del Museo Arqueológico Comarcal de Orihuela. [En línea]. <https://www.facebook.com/adamacorihuela/?_tn__=\%2Cd\%2CP-

R\&eid=ARBpJgZFywni_UIDRWUO2vTYki0cs_5xVc-eqFCFGYQmcmTCm3f46fi4D0GFt048AdzDwAYKy5EKTxn>. [14 de abril de 2020]; y, en segundo lugar, el museo etnológico y de la huerta de Almoradí, que conoció dos ubicaciones diferentes, la última de ellas en el centro cultural de la localidad, donde cesó en sus funciones hace más de una década. Por otro lado, el cuadro incorpora dos museos arqueológicos de la zona (los de Guardamar del Segura y Pilar de la Horadada), que exhiben interesantes colecciones etnográficas en sus salas.
} 
breve presentación - de extensión desigual, en función de la información a la que se ha tenido acceso y en aras de la agilidad del texto final - sobre cada uno de estos museos. Como hipótesis de partida, no obstante, esbozamos el siguiente razonamiento: como quiera que "lo local" - las poblaciones de la comarca estudiada - no es ajeno a "lo global", su forma de proceder tampoco ha de serlo y viene marcada por el modus operandi de este, esto es, el de una sociedad (global) de consumo que busca con rapidez (consumir) productos, la lista de los cuales abarcaría todo aquello susceptible de ser convertido -en un sentido lato- en mercancía. Por tanto, si bien "los pueblos" descubren una identidad, en principio, como freno a la globalidad, lo hacen utilizando las reglas de esta y jugando con sus parámetros.

El resultado es una especie de "carrera" por ver quién es más auténtico y menos global, carrera en la que no suele haber espacio para la reflexión y el debate, pues el primer objetivo es llegar a la meta - abrir el museo -. En el actual escenario mundializado, todo territorio pretende erigirse con voz propia y el hecho de alcanzarla lanza un mensaje tranquilizador a su comunidad, pero oculta el camino recorrido hasta llegar ahí. Como punto de partida, en resumen, consideramos que la práctica totalidad de los museos, colecciones museográficas y espacios etnográficos de la zona estudiada y que se reflejan en el gráfico 1, adolecen de una serie de carencias que lastran su funcionamiento y su papel en el seno de la sociedad donde se asientan.

Tales carencias parten de su propio proceso de gestación y sobre ellos planea la amenaza de reflejar una imagen sesgada del territorio y de su pasado reciente, ofreciendo, por tanto, una historia y un entorno distorsionados, a pesar de la subjetividad inherente a toda iniciativa cultural. Este artículo parte también del reconocimiento a la sociedad huertana, que ha sido capaz de dotarse de unos museos en los que repose su memoria, espacios modestos, pero potencialmente activos, sobre los que cabe aportar sugerencias que los enriquezcan. Precisamente porque se valora la presencia de estos museos en la comarca, es por lo que se es crítico con su andadura, circunstancia que no creemos obedezca a una cuestión de presupuesto, sino a otra muy distinta que radica en su planteamiento y reflexión iniciales, factores que, como intentaremos demostrar a continuación, distan mucho de figurar en las hojas de ruta de la práctica totalidad de los museos del área analizada.

\section{Cuadro 1. Museos, colecciones museográficas y espacios museísticos del Bajo Segura que exhiben colecciones etnográficas, por año de creación.}

\begin{tabular}{|c|c|c|c|}
\hline $\begin{array}{c}\text { MUSEO / } \\
\text { COLECCIÓN }\end{array}$ & MUNICIPIO & CREACIÓN & RECONOCIMIENTO \\
\hline $\begin{array}{c}\text { Museo Etnológico del } \\
\text { Cáñamo y Huerta }\end{array}$ & Callosa de Segura & 1986 & 1994 \\
\hline Museo Arqueológico & $\begin{array}{c}\text { Guardamar del } \\
\text { Segura }\end{array}$ & 1990 & 1993 \\
\hline $\begin{array}{c}\text { Museo Arqueológico- } \\
\text { Etnológico "Gratiniano } \\
\text { Baches" }\end{array}$ & Pilar de la Horadada & 1994 & 1994 \\
\hline $\begin{array}{c}\text { Centro de Visitantes. } \\
\text { P.N. de las lagunas de } \\
\text { La Mata y Torrevieja }\end{array}$ & Torrevieja & 1994 & \\
\hline
\end{tabular}




\begin{tabular}{|c|c|c|c|}
\hline $\begin{array}{c}\text { Museo del Mar y de la } \\
\text { Sal }\end{array}$ & Torrevieja & 1995 & 1998 \\
\hline $\begin{array}{c}\text { Almazara del "Tío José } \\
\text { María" }\end{array}$ & Orihuela & 1997 & No reconocido \\
\hline Museo de la Huerta & Rojales & 2002 & No reconocido \\
\hline $\begin{array}{c}\text { Centro de } \\
\text { Interpretación de la } \\
\text { Industria Salinera }\end{array}$ & Torrevieja & 2002 & No reconocido \\
\hline $\begin{array}{c}\text { Molino Hidráulico } \\
\text { Museo Etnológico }\end{array}$ & $\begin{array}{c}\text { Formentera del } \\
\text { Segura }\end{array}$ & 2004 & No reconocido \\
\hline $\begin{array}{c}\text { Casa-Museo del } \\
\text { Ingeniero Mira }\end{array}$ & $\begin{array}{c}\text { Guardamar del } \\
\text { Segura }\end{array}$ & 2006 & No reconocido \\
\hline Museo de la Huerta & Dolores & 2011 & No reconocido \\
\hline $\begin{array}{c}\text { Museo del Granado } \\
\text { "Conseller García } \\
\text { Antón" }\end{array}$ & Catral & 2013 & No reconocido \\
\hline Memorial de San Isidro & San Isidro & 2015 & No reconocido \\
\hline Museo de La Alquería & Daya Nueva & 2017 & No reconocido \\
\hline
\end{tabular}

Fuente: Conselleria de Educación, Cultura y Deporte. Elaboración propia.

\section{EL BAJO SEGURA}

El Bajo Segura acoge el tramo final del río, que recorre en la provincia de Alicante los últimos treinta y seis quilómetros de su curso. Esta comarca constituye un espacio agrícola de secular importancia, caracterizado por el aprovechamiento a ultranza del agua, sucesivamente reutilizada a través de una compleja red de riego-drenaje, regulada, a su vez, por una tupida red de instituciones y ordenanzas que han llegado hasta nuestros días. De origen islámico, las grandes huertas surgidas en la Península se caracterizan por un aprovechamiento intensivo del agua, condición necesaria dada su ubicación en el área mediterránea, definida por escasez de precipitaciones, acusada evapotranspiración potencial y elevadas insolación y temperatura. En sus tramos medio y bajo, alrededor del río Segura se configuraron históricamente las huertas de Murcia y Orihuela, extensa superficie esencialmente homogénea, si bien dividida administrativamente desde el Medievo, merced al Tratado de Torrellas, que seccionó este territorio al trazar la frontera entre las coronas de Aragón y Castilla.

Este sistema agro-ecológico así constituido irá ampliando progresivamente la red de riego-drenaje, reduciendo a cultivo extensos territorios incultos en una progresión que culminará en el siglo $\mathrm{XX}^{8}$. La construcción de nuevas infraestructuras hidráulicas permitió el avance del regadío en el llano de inundación. La posibilidad de la agricultura y del poblamiento en terrenos otrora baldíos propició la segregación del dilatado término oriolano, donde surgieron asentamientos al albur de coyunturas económicas o

${ }^{8}$ DE GEA, M. La construcción del paisaje agrario en el Bajo Segura. De los orígenes hasta la implantación de la red de riego-drenaje principal en el alfoz oriolano. Alquibla. Revista de Investigación del Bajo Segura, 1995, nº 1, p. 65-100. DE GEA, M. La formación y expansión decisiva de la huerta de Murcia-Orihuela: un enfoque desde la perspectiva de la Orihuela musulmana (siglos VIII - XIII). Alquibla. Revista de Investigación del Bajo Segura, 1997, n 3, p. 155-217. DE GEA, M. Los regadíos de la huerta histórica de Orihuela. En FERRÁNDEZ, T. y DIZ, E. Historia Natural de la Huerta de Orihuela. Orihuela: Ayuntamiento de Orihuela, 2015, p. 215-249. 
demográficas específicas ${ }^{9}$. El progreso del regadío también generó un ordenamiento jurídico, vasto conjunto de ordenanzas y reglamentaciones por las que velaron instituciones como juzgados o sindicatos, cuyos miembros se han venido encargando hasta nuestros días de dirimir los pleitos surgidos en torno al agua, un bien escaso fuertemente regulado.

Por otro lado, ¿cómo ha evolucionado la huerta? Entre otros glosadores de este territorio, sobresale el testimonio de Cavanilles, que se hace eco de su riqueza, pródiga en hortalizas, trigos, maíces, legumbres, cáñamos, linos, frutales, "multitud de moreras" y "naranjos de la China", árboles que describe minuciosamente ${ }^{10}$.

Una huerta, cuya "tierra es tan fértil, que puede servir de abono en la huerta de Valencia" "y que, sin solución de continuidad, se une "hácia poniente con la de Murcia, en la qual se veia una verde alfombra por mas de quatro leguas, y allí la torre y edificios de la capital de aquel reyno" 12 .

Cavanilles lamenta la práctica inexistencia de actividad fabril que observa en una comarca tan rica, también, en la producción de plantas industriales, cuya transformación podría rendir importantes beneficios a las poblaciones de la zona. Así - afirma - "convendria establecer algunas fábricas, de que apénas hay sombra en los pueblos de la huerta, no obstante criarse en ella con abundancia seda, cáñamo y lino, y en los montes de la comarca mucho esparto"13.

El clérigo ilustrado también menciona la presencia de barracas en poblaciones como Almoradí, Catral, Benejúzar o San Bartolomé ${ }^{14}$. Tan solo se detiene a ponderar el urbanismo de Callosa de Segura y Orihuela, núcleos de los que se hace eco de su pujanza. Así, en Callosa habla de la existencia de " 25 telares de lienzo, en 5 calderas de xabon, y como 200 en hacer alpargates"15. De Orihuela, menciona sus "calles espaciosas", en las que "viven $[\ldots .$.$] muchos nobles, hacendados y ricos", junto a "artesanos de varios oficios$ que fabrican lo necesario á los de la ciudad y pueblos de la comarca"16.

Por último, resultan interesantes las alusiones al cordón dunar: “[...] cerros de arena conducida por los vientos. Estos cerros forman un muro que impide ver el mar desde el camino que conduce á Torre la Mata"; y a las salinas de Torrevieja: "Contiguo al cabo Cervér mirando al sudueste se ha ido formando una poblacion llamada Torre vieja, donde 25 años hace habia tres familias, y actualmente 106, ocupadas casi todas en las varias faenas de las salinas que vamos á describir" ${ }^{\prime 1}$.

${ }^{9}$ GIL, A. y CANALES, G. Residuos de propiedad señorial en España. Perduración y ocaso en el Bajo Segura. Alicante: Universidad de Alicante, 2007, p. 21-50.

${ }^{10}$ LACARRA, J., SÁNCHEZ, X. y JARQUE, F. Las Observaciones de Cavanilles. Doscientos años después. Valencia: Fundación Bancaja, vol 4, 1997, p. 372.

${ }^{11}$ Ibidem, p. 388.

${ }^{12}$ Ibidem, p. 372.

${ }^{13}$ Ibidem, p. 382.

14“"...] las pobres habitaciones é indecentes barracas quales se ven en las cercanías de Catrál, Benejuzar, y otras partes"; o bien, en referencia a Catral: "[...] las infelices chozas allí contiguas anuncian la pobreza de los moradores”. Véase: LACARRA, J., SÁNCHEZ, X. y JARQUE, F., op.cit., p. 362, 364 y 386.

${ }^{14}$ Ibidem, p. 386.

${ }^{16}$ Ibidem, p. 390.

${ }^{17}$ Ibidem, p. 392 y 394. 
En el siglo XIX, "seda y barrilla, dos cosechas comerciales punteras, sufren un colapso definitivo y casi total" "18 , habida cuenta del atraso técnico y la competencia oriental, en el caso de la primera, hecho que traerá como consecuencia la decadencia de un cultivo tradicional como el moreral. Por el contrario, el cáñamo, el pimiento de bola y los cítricos irán afianzando su presencia en la vega, junto al "rápido retroceso de los cereales de invierno y la expansión creciente de unas cosechas hortícolas a las que ya no cuadra la vieja denominación de menudo, [...] evolución de cultivos que imprimirá a la huerta su fisonomía actual"19.

Por lo que respecta al "campo", "secano inhóspito y carente de interés económico"20, la Ley de Colonias Agrícolas de 1868 propiciará un auge roturador, con la expansión cerealista y "la arboricultura de escasas exigencias hídricas (olivo, algarrobo, almendro e higuera)"21. No obstante, serán las importantes transformaciones experimentadas en el siglo XX, merced a la elevación de aguas sobrantes del Segura, en un primer momento; $\mathrm{y}$, más recientemente, a la puesta en marcha del trasvase Tajo-Segura, las que modifiquen de manera radical la fisonomía del campo, que junto a una agricultura moderna y comercial presenta una marcada impronta turística ${ }^{22}$.

En las últimas décadas, en definitiva, en el contexto de los cambios acaecidos en el seno de la sociedad española y valenciana, esta comarca ha experimentado una radical transformación, con la terciarización de la economía y el auge de la construcción. A lo largo del siglo XX, la redistribución de la tierra y la transformación de los secanos, gracias a las nuevas infraestructuras hidráulicas; la progresiva mecanización de la agricultura, la desaparición de hábitats tradicionales o la creación de nuevos municipios, entre otros factores, han ido conformando un paisaje distinto, definitivamente alterado en las postrimerías de la anterior centuria con el auge del turismo, la urbanización masiva del territorio -sobre todo en el litoral- y el retroceso de la agricultura como principal sector productivo $^{23}$.

\section{MUSEOS ETNOGRÁFICOS DE LA COMARCA}

Bajo esta denominación se engloba un conjunto de espacios que, con carácter general, muestran "los bienes muebles e inmuebles y los conocimientos y actividades que son o han sido expresión relevante de la cultura tradicional del pueblo español en sus aspectos materiales, sociales o espirituales" ${ }^{24}$. Asimismo, serán "bienes muebles de carácter etnográfico, y se regirán por lo dispuesto en los títulos III y IV de la presente Ley, todos aquellos objetos que constituyen la manifestación o el producto de actividades laborales, estéticas y lúdicas propias de cualquier grupo humano, arraigadas y transmitidas consuetudinariamente" 25 . Por último, "se considera que tienen valor etnográfico y

\footnotetext{
${ }^{18}$ GIL, A. y CANALES, G., op.cit., p. 42.

${ }^{19}$ Ibidem, p. 46.

${ }^{20}$ CANALES, G. El Bajo Segura. En UROZ, J. Historia de la Provincia de Alicante. Murcia: Ediciones Mediterráneo, 1985, vol. I², p. 398.

${ }^{21}$ GIL, A. y CANALES, G., op.cit., p. 46.

${ }^{22}$ Ibidem, p. 50.

${ }^{23}$ CANALES, G. El Bajo Segura. Estructura espacial, demográfica y económica. Alicante: Cam Fundación Cultural, Universidad de Alicante, 1995, p. 136.

${ }^{24}$ Ley 16/1985, de 25 de junio, del Patrimonio Histórico Español. [En línea]. <https://www.boe.es/eli/es/1/1985/06/25/16/con>. [2 de abril de 2020].

${ }^{25}$ Ibidem.
} 
gozarán de protección administrativa aquellos conocimientos o actividades que procedan de modelos o técnicas tradicionales utilizados por una determinada comunidad" 26 . A partir de esta definición, a continuación, se describe la totalidad de espacios comarcales que podemos englobar, grosso modo, en esta tipología museística, considerando, como se ha dicho, que al mostrar las actividades tradicionales de la comunidad, los "museos" etnográficos deben de explicar también el entorno en el que esta se asienta. Hemos creído oportuno agruparlos - por año de creación - en las siguientes categorías, descritas sucesivamente:

Museos y colecciones museográficas reconocidas:

- Colección Museográfica. Museo Etnológico Municipal del Cáñamo y Huerta (Callosa de Segura).

- Museo Arqueológico de Guardamar del Segura.

- Museo Arqueológico-Etnológico "Gratiniano Baches" (Pilar de la Horadada).

- Museo del Mar y de la Sal (Torrevieja).

- Museo de la Huerta de Rojales.

Espacios museísticos no reconocidos. Los hemos dividido en tres apartados:

- Espacios museísticos sobre la Huerta:

- Museo de la Huerta de Cox.

- Museo de la Huerta de Dolores.

- Espacios museísticos de carácter monográfico, dedicados a cultivos o actividades específicas:

- Almazara del "Tío José María" (Orihuela).

- Molino Hidráulico Harinero (Formentera del Segura).

- Centro de Interpretación del Granado "Conseller García Antón" (Catral).

- Nuevos espacios museísticos:

○ Casa-Museo del Ingeniero Mira (Guardamar del Segura).

- Memorial de San Isidro.

- Museo de La Alquería (Daya Nueva).

Centros de Visitantes de Parques Naturales.

\section{Museos y colecciones museográficas reconocidas}

Colección Museográfica. Museo Etnológico Municipal del Cáñamo y Huerta (Callosa de Segura)

El cáñamo, conocido y utilizado desde antiguo por producir una importante fibra textil, ha constituido uno de los cultivos más secularmente extendido por el Bajo Segura, motivo

${ }^{26}$ Ibidem. 
por el cual lo que podríamos denominar como "cultura del cáñamo"27 se encuentra hondamente enraizada en la sociedad huertana.

Durante el siglo XX, el cultivo del cáñamo conocerá su etapa de mayor prosperidad en la provincia de Alicante, una de las principales zonas productoras del país, auge propiciado tanto por las coyunturas bélicas internacionales, ${ }^{28}$ como por el estallido y posteriores consecuencias de la Guerra Civil. Dada la importancia de esta planta de la que, entre otros aprovechamientos, se obtenía todo tipo de hilaturas y cuerdas (utilizados principalmente para la navegación, así como para la elaboración de redes y sacos) y cuyos sobrantes se empleaban, además, para trenzar sogas con las que confeccionar suelas de alpargata, durante la posguerra su cultivo se extenderá por amplias zonas de la provincia, principalmente del Bajo Segura y, en menor medida, del Bajo Vinalopó ${ }^{29}$.

A partir de la década de los sesenta del siglo XX, con la progresiva generalización de las fibras sintéticas, el cultivo del cáñamo desapareció y, con él, todo el acervo tradicional relacionado con esta actividad. Callosa de Segura, importante centro productor de hilaturas y, en general, de productos derivados de esta planta, continuó desarrollando una destacada actividad fabril, ahora con nylon y otros materiales, y el cáñamo pasó a ser un recuerdo en la memoria colectiva de la población.

La colección museográfica del cáñamo se ubica en el antiguo matadero de la población y su origen se debe a la actividad del grupo "Amigos del Patrimonio", que llevó a cabo una labor de concienciación de la sociedad local, cuya aportación donando piezas fue decisiva. Así, la cultura del cáñamo comenzó a recuperarse en este municipio, que pronto reivindicó la apertura de un museo, un lugar que albergara todos aquellos elementos relacionados con el cultivo $\mathrm{y}$, sobre todo, con la manipulación de esta planta, indisolublemente unida a la historia de Callosa.

En el museo se exhibe, principalmente, la cultura material relacionada con el proceso tradicional de transformación del cáñamo, si bien también introduce su mecanización, incluyendo aspectos como la sustitución paulatina de las fibras naturales por materiales sintéticos o las enfermedades profesionales. Se divide en dos grandes secciones: la agrícola, que engloba la huerta, el embalsado y el agramado; y la industrial, con el espadado, el rastrillado, el repasado y, por último, el hilado, el corchado y la fabricación de redes.

Previa concertación, en el museo se llevan a cabo demostraciones de las actividades relacionadas con el cáñamo, realizadas por antiguos trabajadores, integrados en la Escuela de los Trabajos Artesanales del Cáñamo, surgida hace unos años para divulgar el acervo cultural en torno a esta planta. Además, en ocasiones tiene lugar otra actividad en la que, junto al museo, se visitan algunos inmuebles relacionados con lo que fueron las tareas del cáñamo, como una balsa o un obrador, lista ampliada en los últimos años con la inclusión del Mirador de los Hiladores, en el acceso a una antigua fábrica de hilado ${ }^{30}$. No obstante,

\footnotetext{
${ }^{27}$ BROTONS, B. y SOLER, A. S 'ha perdut una cultura del Camp d'Elx. Elche: Caja de Ahorros de Alicante y Murcia, 1986, p. 87-89.

${ }^{28}$ ALBERT, R.F. La industria del cáñamo en Callosa de Segura (Alicante). Catalogación y estudio de utillajes y otros productos derivados de esta industria artesanal. Alicante: Instituto de Cultura «Juan GilAlbert», Diputación Provincial de Alicante, 1989, p. 24 y 30.

${ }^{29}$ Ibidem, p. 31.

${ }^{30}$ Información. [En línea]. <https://www.diarioinformacion.com/vega-baja/2017/02/16/nuevo-miradorhiladores-canamo-costara/1861078.html>. [2 de abril de 2020].
} 
al realizarse de manera ocasional, estos itinerarios no han llegado a configurarse adecuadamente, con el agravante de que los bienes que se exhiben no se encuentran protegidos $^{31}$. Sería conveniente que, una vez diseñadas - señalizadas, adaptadas, difundidas... -, estas rutas pudieran ofertarse como recurso turístico de la población.

\section{Museo Arqueológico de Guardamar del Segura}

Este museo municipal se ubica en la Casa de Cultura de la localidad. Si bien centra su discurso en los fondos procedentes de las excavaciones que se realizan en el municipio, también expone una interesante colección etnográfica en la sala correspondiente a la época contemporánea.

A través de diferentes espacios - algunos renovados, como el dedicado al medio natural, a la cultura fenicia o a la íbera -, el museo nos introduce en la historia de Guardamar, siguiendo un discurso diacrónico que comienza en la sala del medio físico, donde se exhiben hallazgos paleontológicos junto a aquellos procedentes de los yacimientos prehistóricos existentes en la población. El alcance desigual de la intervención hace que nos encontremos ante unas salas que presentan una museografía no homogénea. Así, las zonas renovadas muestran un planteamiento moderno, en el que la exhibición de las colecciones se enriquece con el uso de medios audiovisuales, ausentes en las salas antiguas.

Los fondos contemporáneos se ubican en uno de estos espacios, de manera convencional y con escasa información, al igual que en otros museos de la zona ${ }^{32}$. En esta sala, correspondiente a los siglos XIX y XX, se describe tanto el entorno socioeconómico de Guardamar, como su vida tradicional. Así, aperos de labranza, cerámicas y ajuares domésticos introducen la vida cotidiana del pasado reciente. Junto a esta colección, el museo explica el urbanismo contemporáneo de la localidad - tras el terremoto de 1829, que la destruyó s $^{33}$ - y hace referencia a la repoblación forestal de las dunas, de tanta trascendencia para el devenir del pueblo, que a punto estuvo de quedar sepultado bajo la arena. En este sentido, no obstante, debemos señalar que la información, tanto desde el punto de vista museológico como museográfico, que se ofrece de ambos acontecimientos - los más relevantes, sin duda, de la historia reciente del municipio - es a todas luces insuficiente, con textos escuetos, redactados solo en castellano y con unas reproducciones fotográficas de escasa calidad. Somos conscientes, por un lado - como se ha mencionado -, que el centro se encuentra inmerso en un proceso de reformas; y, por otro, que, recientemente (2020), el municipio ha inaugurado la renovación de la Casa-Museo Ingeniero Mira, cuya visita se realiza conjuntamente con la del museo; y en esta Casa-

\footnotetext{
${ }^{31}$ CANALES, G. y RUÍZ, E. La Huerta del Bajo Segura (Alicante), un patrimonio cultural en peligro. Reflexiones sobre un proyecto museológico integral. Investigaciones Geográficas, 2011, no 54, p. 204-248. Por otro lado, el único inmueble relacionado con el cáñamo que consta en los listados de la Conselleria de Educación, Cultura y Deporte es una balsa, recogida en el inventario sectorial de etnología, no incluido en el Inventario General del Patrimonio Cultural Valenciano. Véase: Generalitat Valenciana. Conselleria de Educación, Cultura y Deporte. [En línea]. <http://www.ceice.gva.es/es/web/patrimonio-cultural-ymuseos/etnologia>. [2 de abril de 2020].

${ }^{32}$ Esta sala de contenido etnográfico es similar, por ejemplo, a la del museo "Gratiniano Baches", de Pilar de la Horadada, del que se hablará más adelante.

${ }^{33}$ Está previsto crear un museo sobre el terremoto de 1829 en Almoradí, población que también resultó arrasada por él. Este museo se ubicaría en la única de las viviendas construidas tras el seísmo que permanece en pie, adquirida en 2018 por el Ayuntamiento de esa población. Información. [En línea]. <https://www.diarioinformacion.com/vega-baja/2018/12/20/almoradi-adquiere-primera-viviendasocial/2099614.html>. [14 de abril de 2020].
} 
Museo, como veremos en las páginas que siguen, ya se explican sobradamente los acontecimientos por los que atravesó la población durante los dos últimos siglos.

El museo realiza exposiciones temporales y organiza actividades didácticas entre los escolares. Desde su página web también informa del patrimonio existente en el municipio y de otras actividades culturales relacionadas con la historia local, como la denominada Senda de la Historia, recorrido realizado en un tren turístico que visita parte de los yacimientos y lugares emblemáticos de la localidad (rábita califal, dunas, castillo...), iniciativa que se gestiona junto a la Concejalía de Turismo. Estos itinerarios, ampliados (diseño urbano de Larramendi ${ }^{34}$, infraestructuras de Riegos de Levante...), también se encuentran recogidos en Memoria de Arena, renovada campaña de difusión del patrimonio guardamarenco - en castellano, valenciano e inglés -, señalizado con códigos QR.

\section{Museo Arqueológico Etnológico "Gratiniano Baches” (Pilar de la Horadada)}

Pilar de la Horadada perteneció a Orihuela hasta 1986, año en el que se segregó de la capital comarcal, tras un dilatado período de tiempo en el que se sucedieron las reivindicaciones vecinales. Apenas ocho años más tarde, el municipio inauguraba un museo municipal, fruto de las donaciones y depósitos de particulares, que integraba todas aquellas secciones (medio ambiente, fósiles, arqueología, etnología y numismática) ${ }^{35} \mathrm{con}$ las que se pretendía mostrar la identidad y características de la localidad. El centro recibió el nombre de Gratiniano Baches (1878-1939), intelectual vinculado a la localidad, del cual reproducen su despacho. Este museo ocupa una sala de la Casa de Cultura, edificio que alberga otros usos, como un espacio dedicado al escultor Sánchez Lozano - integrado en el propio museo - o una biblioteca.

La colección es heterogénea y no se exhibe adecuadamente. Por lo que respecta a la colección de etnografía, las secciones se dividen en: esparto, útiles domésticos, textiles, elaboración del vino y aperos y útiles agrícolas. Las cartelas son rudimentarias y apenas recogen información; algunas se encuentran deterioradas.

En la página web municipal se afirma que "desde la dirección del museo se coordinan otras labores relacionadas con el mismo, como la función científica que desarrollan las excavaciones arqueológicas, las cuales incrementan el fondo museístico" ${ }^{36}$. En cuanto a la investigación, la directora del museo, García Samper, ha publicado valiosas monografías sobre la historia de la localidad ${ }^{37}$.

\footnotetext{
${ }^{34}$ José Agustín de Larramendi (1769-1848) fue el ingeniero que dirigió la planificación urbanística, tanto de Guardamar como de otros municipios del Bajo Segura, tras el terremoto que asoló la zona en 1829. Véase: CANALES, G. La catástrofe sísmica de 1829 y sus repercusiones. Almoradí: Excma. Diputación Provincial de Alicante, Excmo. Ayuntamiento de Almoradí, Universidad de Alicante, 1999. 353 p.

${ }^{35}$ Ayuntamiento de Pilar de la Horadada. [En línea]. <http://www.pilardelahoradada.org/areas/cultura/museo>. [6 de abril de 2020].

${ }^{36}$ Ibidem.

${ }^{37}$ Entre otras, véase: GARCÍA, M. Arroz con leche: homenaje a los protagonistas de las duras décadas de los años 40 y 50 en Pilar de la Horadada. Pilar de la Horadada: Ayuntamiento de Pilar de la Horadada, 2003. 324 p. GARCÍA, M. El desfile de carrozas de Pilar de la Horadada: Una manifestación cultural. Pilar de la Horadada: Ayuntamiento de Pilar de la Horadada, 2014. 208 p.
} 
Por otro lado, la página web del Ayuntamiento de la localidad publicita unas rutas por su término municipal, tanto para realizarse a pie como en bicicleta, entre otras, la del Pinar de Campoverde, el Río Seco o la fachada litoral ${ }^{38}$.

\section{Museo del Mar y de la Sal (Torrevieja)}

El museo del mar y de la sal alberga un contenido fundamentalmente etnográfico que pretende reflejar la historia de este municipio, incidiendo en la impronta que el mar ha ejercido en su génesis y desarrollo, desde la creación de su primer caserío en el setecientos.

De las secciones en las que se divide, las más directamente relacionadas con la etnografía e historia de la población son las de navegación de cabotaje, velería, carpintería de ribera, pesca artesanal y salinas, secciones constreñidas en un espacio a todas luces reducido, habida cuenta de lo inadecuado de las instalaciones donde se encuentra el museo, que los trípticos promocionales - editados en castellano, francés, inglés y alemán - anuncian como provisionales. El centro muestra, además, numerosos dioramas y maquetas, así como antiguas fotografías y piezas relacionadas con la Armada Española.

Se trata de un museo abarrotado que resulta caótico en su exposición, por otra parte, meramente contemplativa por un público compuesto, en mayor medida, por escolares y turismo residencial. Es de desear que, en su ubicación definitiva, el museo exhiba adecuadamente sus colecciones $\mathrm{y}$, sin competir con otros monográficos de la ciudad, las enriquezca con secciones sobre el entorno comarcal - Campo de Salinas - o la ciudad turística del siglo $\mathrm{XX}$, entre otras.

Por otro lado, en el recinto portuario de Torrevieja ${ }^{39}$, el centro muestra los denominados "museos flotantes", formados por la patrullera Albatros III y el submarino S-61 Delfín, barcos que conforman un interesante conjunto patrimonial vinculado a Torrevieja y exhibido en su puerto. La patrullera perteneció al Servicio de Vigilancia Aduanera y fue cedida al Ayuntamiento de Torrevieja por la Agencia Tributaria. El submarino, cedido por el Ministerio de Defensa, constituye el primer buque de la Armada convertido en museo. La relación de este navío con la ciudad salinera se remonta a 1974, fecha en la que se le entregó en la ciudad la bandera de combate.

Mención aparte merece la réplica del pailebote Pascual Flores, velero construido a comienzos del siglo XX en astilleros torrevejenses, adquirido en la década de los noventa por el Ayuntamiento de la ciudad, donde llegó en $1999^{40}$. Pese al desembolso que supuso la compra del barco, la pésima gestión realizada desde la administración lo redujo a escombros, en medio de la desidia de sus responsables y de las críticas de la opinión pública. Más tarde, el velero fue reconstruido, si bien no se puede visitar. En la actualidad, el buque permanece anclado junto al resto de los museos flotantes, en espera de su apertura al público o de cualesquiera otros usos que se le quiera dar.

\footnotetext{
${ }^{38}$ Ayuntamiento Pilar de la Horadada. [En línea]. <http://www.visitpilardelahoradada.com/es/que_ver_hacer/rutas>. [16 de abril de 2020].

${ }^{39}$ MARTÍNEZ, R. Museos que flotan. La Verdad, no 34.660, 6 de septiembre de 2012, p. 19.

${ }^{40}$ Información. [En línea]. <http://www.diarioinformacion.com/vega-baja/2013/03/10/capricho-46millones-dique-muerto/1351989.html>. [7 de abril de 2020].
} 
Otro elemento singular que se muestra en el muelle es un curioso remolcador, ya en desuso, que se utilizó en las salinas. Se trata de una pequeña barca pintada de colores con el fin de que pudiera distinguirse desde cualquier punto de la laguna - e impulsada por ruedas de paletas, para no embarrancar en aguas someras. En la misma zona también se expone una selección de armamento naval y diferentes elementos que formaron parte de buques de guerra.

\section{Museo de la Huerta de Rojales}

El museo municipal de la huerta de esta población se ubica en la gran hacienda de los Llanos o de don Florencio, explotación de más de treinta mil metros cuadrados de superficie $^{41}$. Ocupa la casa principal y edificios aledaños de la mencionada hacienda y constituye "un conjunto arquitectónico, agroecológico y ecomuseístico (entendido como experiencia histórica de cada pueblo interpretando su relación con el ámbito natural, social y cultural) de gran interés" $"$. Sus colecciones muestran piezas procedentes de "los trabajos de la Huerta, las actividades artesanales (aperador, corrionero, etc.), los enseres de la casa (ajuar, mobiliario, estancias, etc.), vehículos de transporte tradicional y aparejos de bueyes y caballerías, el aceite, el ciclo del cereal, el helado, la caza, botica, etc."43.

El origen de las colecciones se debe a la propia actividad de la institución y a los habitantes de Rojales, que durante años han venido donando objetos. Desde el museo parte una ruta que recorre la huerta tradicional del entorno de la localidad. Probablemente, Rojales, junto a Guardamar y Pilar de la Horadada, es uno de los municipios más activos en cuanto a la puesta en valor de su patrimonio a través de una serie de itinerarios. Además del de la huerta, hay otros que recorren el conjunto monumental hidráulico urbano o las cuevas del Rodeo.

Este museo se configura como un centro de dilatada trayectoria y actividad creciente (exposiciones, ciclos de conferencias o edición de libros). Constituido gracias a la colaboración vecinal y ocupando una antigua hacienda - estamos ante un museo "de sitio" - que, a su vez, configura a su alrededor una ruta patrimonial en torno a la naturaleza, la agricultura y el paisaje, este museo conforma una iniciativa interesante en cuanto a la puesta en valor de la huerta del Segura. No obstante, su criterio expositivo es similar al de otros centros contemplativos, en los que se muestra un espacio sacralizado e inaccesible, ausente de crítica y ajeno, por tanto, a la problemática que lo acosa, cuya responsabilidad, precisamente, también recae en el público que acude.

\section{Espacios museísticos no reconocidos}

\section{Espacios museísticos sobre la Huerta}

En este primer apartado incluimos los museos de la huerta de Cox y Dolores, centros modestos de similar factura sin, prácticamente, actividades ni personal adscrito. Como tendremos ocasión de comprobar, pese a sus diferencias formales, todos los museos de la huerta existentes en el Bajo Segura obedecen a un discurso similar, centrado en exhibir en una suerte de recreación la cultura material relacionada con la vega y su entorno.

\footnotetext{
${ }^{41}$ Ayuntamiento de Rojales. [En línea]. < http://www.rojales.es/museo-de-la-huerta/>. [7 de abril de 2020].

${ }^{42}$ Museos de Rojales. [En línea]. <http://museosderojales.es/museo-de-la-huerta/>. [7 de abril de 2020].

${ }^{43}$ Ibidem.
} 


\section{Museo de la Huerta de Cox}

También conocido como Museo Etnológico de Cox, este centro se ubica en un molino de viento, al parecer, construido en su origen por los repobladores castellano-manchegos que se establecieron en este municipio tras la expulsión de los moriscos ${ }^{44}$. Se trata de uno de los escasos molinos de viento que existen en la zona objeto de nuestro estudio, en la que, al menos, se emplazan cuatro más, en Rojales, San Miguel de Salinas, Los Montesinos y Torrevieja.

El museo exhibe unas colecciones misceláneas, cuyas piezas fueron donadas por vecinos de la localidad. La falta de espacio condiciona la exposición, que se distribuye por las dos primeras plantas del edificio, quedando vacía la última, pudiéndose contemplar en este espacio la parte interior de la cubierta. En la primera planta se encuentra el utillaje agrícola y ganadero; en la segunda, el menaje de hogar y piezas relacionadas con distintas actividades artesanales, como la apicultura y el manipulado del cáñamo. En el museo también se muestran fotografías antiguas y tanto los textos como las cartelas y el tríptico informativo están redactados solo en castellano.

Al igual que otros museos analizados en el presente trabajo, el de Cox no presenta actividad aparente. El molino permanece habitualmente cerrado al público, que puede acceder a él previa solicitud - en ocasiones, meramente verbal - realizada ante el Ayuntamiento de la localidad (área de Turismo). Como ocurre, también, en otros museos de la comarca, el aquí analizado carece de un inventario o catálogo razonado de las colecciones; tampoco hay política de adquisiciones. La difusión del museo es deficiente, si bien se promociona en la página web municipal y, recientemente, se ha integrado en una ruta por la huerta trazada conjuntamente con el vecino municipio de Granja de Rocamora. Diseñada por alumnos de un taller de empleo - Vega Baja Turismo y Ocio II - gestionado por el Consorcio para el Desarrollo Económico de la Vega Baja (Convega), esta ruta circular de alrededor de $14 \mathrm{~km}$ de longitud recorre ambas poblaciones y muestra su patrimonio natural, etnológico o arquitectónico ${ }^{45}$.

\section{Museo de la Huerta de Dolores}

Este museo ocupa un edificio situado en las afueras de esta población, en un entorno de reciente urbanización. Este edificio, de nueva construcción, es una réplica de un antiguo inmueble que existió en el municipio, ya derribado, perteneciente a un importante propietario de tierras.

El museo se divide en una serie de salas en las que, como en el anterior, se muestra la habitual "mescolanza identitaria", observada también en otros centros. Así, sus instalaciones acogen desde maquetas relativas a actividades tradicionales de la zona, hasta los antiguos aperos y herramientas relacionadas con estos trabajos.

El origen de este museo se debe al trabajo desarrollado por la Asociación para la Recuperación del Patrimonio Histórico-Cultural de la Vega Baja del Segura, entidad con sede en Dolores que, desde hace años, viene desarrollando una activa labor en cuanto a

\footnotetext{
${ }^{44}$ Ayuntamiento de Cox. [En línea]. 〈http://www.cox.es/el-municipio/turismo/museos/>. [6 de abril de 2020].

${ }^{45}$ Información. [En línea]. <https://www.diarioinformacion.com/vega-baja/2017/05/30/granja-coxestrenan-ruta-huerta/1900100.html>. [6 de abril de 2020].
} 
la protección del patrimonio. Ellos son los propietarios de los fondos que nutren el museo, depositados en este mediante un convenio de colaboración firmado con el Ayuntamiento de la población (el museo es de titularidad municipal). Al parecer, la mencionada asociación organizaba exposiciones en la localidad con motivo de determinados eventos y festividades, hecho que, con el tiempo, dio pie a la corporación municipal a solicitar a este colectivo una colaboración de mayor calado, siendo el museo de la huerta resultado de esta iniciativa. Esta asociación cuenta con numerosos fondos - al margen de los que se exhiben en el museo -, fruto de su intensa labor "recolectora" desarrollada tanto en la comarca del Bajo Segura como en el Bajo Vinalopó. Asimismo, disponen de una colección fotográfica.

Actualmente, al parecer, el museo de la huerta solo abre los sábados por la mañana y es atendido por personal de turismo. Por otro lado, sus fondos sí se encuentran inventariados $\mathrm{y}$, según fuentes municipales, se ha gestionado su reconocimiento como colección museográfica ${ }^{46}$. Desde 2017, el municipio organiza rutas de observación de aves en el entorno del Parque Natural de El Hondo, cuyos itinerarios, si bien atraviesan la huerta, se orientan al turismo ornitológico, pensado para atraer a los residentes foráneos de la zona ${ }^{47}$.

\section{Espacios museísticos de carácter monográfico}

Entre los espacios no reconocidos encontramos tres de carácter monográfico, como se ha mencionado, dedicados al olivo, al cereal y al granado. Se trata de la almazara del "Tío José María", en Orihuela; del molino hidráulico de Formentera del Segura y del Museo de Interpretación del Granado “Conseller García Antón”, en Catral.

El primero de ellos se ubica en la pedanía oriolana de La Aparecida, próximo a la carretera N-340. La almazara conforma una colección museográfica de carácter etnográfico y de titularidad privada, formada también por un horno, una tienda-bar y una vivienda, conjunto integrado en un mismo edificio. El origen de la almazara se remonta a $1759 \mathrm{y}$ estuvo en activo hasta mediados del siglo XX, siempre en manos de la misma familia. La apertura del horno y de la tienda-bar ocurrió ya en el novecientos (1918), aunque apenas estuvieron en funcionamiento unos años, pues en 1925 inauguraron un nuevo establecimiento junto a la mencionada carretera. La vivienda sí continuó habitada durante años por la familia del actual propietario y en la actualidad se ha musealizado con mobiliario original ${ }^{48}$.

Antaño común, principalmente en el secano - la toponimia nos señala que menudearon las almazaras en el campo $^{49}$-, la presencia del olivo en la comarca se reducirá drásticamente a lo largo del siglo XX. Algunos olivares relictos sobrevivieron en "las cañadas y en algún piedemonte donde se aprovechan las aguas de arroyada que circulan

\footnotetext{
${ }^{46}$ Ayuntamiento de Dolores. [En línea]. <http://www.dolores.es/coleccion-museografica-museo-de-lahuerta/>. [6 de abril de 2020].

${ }^{47}$ Ayuntamiento de Dolores. [En línea]. <http://www.dolores.es/ruta-ornitologica-por-la-huerta-de-doloresy-el-parque-natural-el-hondo/>. [7 de abril de 2020].

${ }^{48}$ Almazara del Tío José María. [En línea]. <https://www.gluseum.com/ES/LaAparecida/284203421747865/Almazara-del-t\%C3\%ADo-Jos\%C3\%A9-Mar\%C3\%ADa>. [7 de abril de 2020].

${ }^{49}$ VERA, J.F. Tradición y cambio en el campo del Bajo Segura. Alicante: Instituto de Estudios Alicantinos, Diputación Provincial de Alicante, 1984, p. 104 y 110.
} 
esporádicamente" ${ }^{, 50}$. Así se explica la presencia de esta almazara en La Aparecida, en el glacis de la Sierra de Orihuela, espacio tradicionalmente vinculado a los cultivos característicos del secano mediterráneo ${ }^{51}$.

La almazara es el elemento más sobresaliente del conjunto etnográfico y en ella se exhiben, en su integridad, espacios y herramientas originales, tales como el malacate, las prensas o el molino de molturar aceituna, entre otras. Se trata de las piezas originales que estuvieron en activo hasta que, a mediados del siglo XX, la almazara cerró definitivamente sus puertas. Junto a estas piezas, se muestran otras relacionadas con actividades llevadas a cabo en la zona, como trillos, agramadoras, desgranadoras de maíz, cencerros, esquilas, etc. La colección también incluye una medida de arroz procedente de Japón y un trillo castellano de pedernales.

Aunque la almazara había sido conservada, al parecer, intacta por sus dueños, habida cuenta del componente sentimental de la instalación - se trata de un museo que rinde tributo a la memoria familiar y a la actividad desarrollada durante dos siglos -, fue a partir de 1997 cuando el actual propietario decidió llevar a cabo una primera restauración del edificio y su existencia comenzó a ser conocida por la gente del entorno. Desde entonces, son frecuentes las visitas de colegios y de particulares, que reciben las explicaciones de don José María López.

El molino hidráulico de Formentera, cuyo origen se remonta, probablemente, al siglo XVIII ${ }^{52}$, está situado en el barrio del Molino, en la zona conocida tradicionalmente como "El Pantano", en un amplio meandro del río Segura ${ }^{53}$. Forma parte de un conjunto hidráulico constituido, además, por el azud y la noria de Benijófar. El molino aparece relacionado en el listado de bienes de relevancia local de la Conselleria de Educación, Cultura y Deporte, tanto en el municipio de Benijófar ("molino árabe"), como en el de Formentera del Segura ("molino hidráulico"), atribuyéndoselo ambas poblaciones en sus respectivos términos municipales. Asimismo, la noria está inventariada en el listado de bienes inmuebles de etnología de la Conselleria ${ }^{54}$.

Se trata de un molino de agua de dos piedras, instalado en tierra y de rodete horizontal. El azud o presa de Formentera retenía el agua y elevaba su nivel, con el fin de utilizarla tanto para el regadío como para la molienda. En relación a esta, el agua era desviada por el canal de captura hacia el cárcavo, donde se encontraba el mecanismo principal para la producción de energía hidráulica. En el cárcavo, los rodetes giraban impulsados por la fuerza del agua y por un mecanismo de transmisión ponían en funcionamiento la maquinaria de la sala de molido. Este molino, que estuvo en activo hasta la segunda mitad del siglo XX, se encontraba en estado ruinoso, si bien tras su rehabilitación, abrió sus puertas en 2004.

\footnotetext{
${ }^{50}$ Ibidem, p. 110.

${ }^{51}$ DIZ, E. Poblamiento y usos tradicionales en la Sierra de Orihuela. En: MARTÍNEZ, S. y FERRÁNDEZ, T. Historia Natural de la Sierra de Orihuela. Orihuela: Ayuntamiento de Orihuela, 2011, p. 85.

${ }^{52}$ MARTÍNEZ, R. El molino hidráulico de Formentera. Un patrimonio etnológico en peligro. Alquibla. Revista de Investigación del Bajo Segura, 1999, nº 5, p. 505-519. Véase también: GIL, A. y CANALES, G., op.cit., p. 191-202 y 331-367.

${ }^{53}$ Ayuntamiento de Formentera del Segura. [En línea]. <http://www.formenteradelsegura.es/turismo/quever-que-visitar-que-disfrutar/patrimonio-artistico-cultural/molino-hidraulico-harinero/>. [7 de abril de 2020].

${ }^{54}$ Generalitat Valenciana. Conselleria de Educación, Cultura y Deporte. [En línea]. <http://www.ceice.gva.es/es/web/patrimonio-cultural-y-museos/inventario-general>. [9 de abril de 2020].
} 
Según el díptico informativo - también la página web de Conselleria ofrece información al respecto -, el interior del edificio consta de una sala de exposición de utillaje agrícola. Asimismo, se muestra "la casa restaurada del molinero" y "el mobiliario que encontramos en el interior ha sido donado por vecinos del municipio" "55, con el fin de amueblar sus diferentes estancias, como la cocina, los dormitorios o las cuadras. En cuanto a la maquinaria del molino, esta se ha reproducido fielmente, ante la imposibilidad de restaurar la existente en su interior. El edificio no se encuentra abierto al público y solo se permite la entrada de forma discrecional, en función de algún evento o festividad concreta, con motivo de la cual abre sus puertas.

Como se ha apuntado más arriba, otro museo dedicado a un cultivo específico es el Centro de Interpretación del Granado "Conseller García Antón”, de Catral. Actualmente cerrada, esta "tienda-museo" se inauguró en 2013 (estuvo abierta al público hasta 2019) y se situaba en las instalaciones de la empresa Vitalgrana, dedicada a la producción de derivados de la granada mollar de Elche.

El granado es un árbol mediterráneo, presente desde la Antigüedad en las comarcas del Bajo Vinalopó y Bajo Segura ${ }^{56}$. En los últimos años ha experimentado un importante crecimiento en la zona, convirtiéndose en el principal cultivo arbóreo de municipios cercanos, como Elche ${ }^{57}$. Aunque la fruta se exportaba mayoritariamente en fresco, últimamente han comenzado a procesarse sus derivados en empresas como Vitalgrana, cuya planta ha albergado en sus instalaciones (hasta fechas recientes) un modesto centro de interpretación del granado, anejo a una tienda que comercializa sus productos.

Con una museografía pretendidamente original, este espacio exhibía una reducida selección de piezas etnográficas, buscando incentivar el consumo de los procesados que elaboraba la planta, a los que enriquecía con la vitola de auténticos o tradicionales. De pequeñas dimensiones, el denominado "museo" introducía el cultivo del granado y las propiedades de su fruto con una serie de grandes paneles retroiluminados, con textos y fotografías. Se recreaba una acequia cubierta con una pérgola, junto a la que se exhibían dos brencas de piedra y una serie de piezas sin relación aparente con el cultivo del granado, como una zafra, una báscula o algunas planchas de carbón, entre otros objetos, todos ellos sin restaurar y sin cartela.

Previa reserva, los grupos accedían a sus instalaciones, donde recibían las explicaciones de un guía. Según fuentes de la empresa, los centros educativos constituían el grueso de sus visitas, sobre todo los procedentes de Elche, Orihuela y, en general, del Bajo Segura. En cuanto a las de origen extranjero, predominaban de Francia, Alemania y los países nórdicos. La visita resultaba completa, pues en primer lugar se visitaba un huerto de granados para, a continuación, acceder al museo y, por último, a la fábrica. Como se ha mencionado, este tipo de "museos" creados en fábricas o grandes comercios pretenden otorgar un valor añadido a sus productos, propiciando la venta. Recientemente, tras el cambio de gerencia de la empresa (2019), el centro de interpretación del granado cerró sus puertas sin que, al parecer, esté prevista su reapertura.

\footnotetext{
${ }^{55}$ Ayuntamiento de Formentera del Segura. [En línea]. <http://www.formenteradelsegura.es/turismo/folletos-turisticos/>. [25 de abril de 2020].

${ }^{56}$ GRAU, I. y MORATALLA, J. El campo y la agricultura. En Iberia, Hispania, Spania. Una mirada desde Ilici. Alicante: Caja de Ahorros del Mediterráneo, 2004, p. 122.

${ }^{57}$ Granada Mollar de Elche. [En línea]. <http://www.granadaselche.com/granada>. [7 de abril de 2020].
} 


\section{Nuevos espacios museísticos}

Por último, encuadramos tres espacios de reciente apertura en un mismo apartado. Se trata de centros diseñados con un mayor dinamismo e implicación social - sobre todo los de Daya Nueva y San Isidro, impulsados desde la Cátedra Arzobispo Loazes, de la Universidad de Alicante -; espacios que aspiran a erigirse en dinamizadores culturales y turísticos de sus respectivos municipios, que se han implicado en su propia gestación. Ambos centros, en definitiva, buscan mostrar un discurso atractivo que actúe como revulsivo para sus respectivas poblaciones, invitándolas no solo a su contemplación, sino a su activa participación donando objetos o asistiendo a los actos programados. Por otro lado, en la Casa-Museo del Ingeniero Mira se ubica la oficina de turismo de Guardamar del Segura y tanto su planteamiento como la procedencia de la mayor parte de sus fondos - de la familia Mira y de propiedad municipal -, definen un espacio de características distintas.

\section{Casa-Museo del Ingeniero Mira (Guardamar del Segura)}

Esta casa-museo que lleva el nombre del ingeniero aspense Francisco Mira (1863-1944) se construyó en 1906, como lugar de trabajo y hospedaje, tanto para el artífice de la repoblación forestal llevada a cabo en las dunas de Guardamar, como para los guardas que la hicieron posible.

En la casa, de dos plantas y azotea, se ubica actualmente la oficina de turismo de la población. Consta de un patio interior y se encuentra rehabilitada, habiéndose recuperado parte de su estructura original. En sus distintas salas se explica el proceso de repoblación forestal llevado a cabo en las dunas de Guardamar entre los siglos XIX y XX, dada la grave situación por la que atravesaba este municipio ante el avance de las dunas, que ya habían sepultado diferentes zonas de aquel ${ }^{58}$.

La primera musealización de la vivienda se realizó en 2006, con textos sobre paneles, redactados en castellano, valenciano e inglés. También se mostraban fotografías, tanto de la repoblación como del Guardamar de la época, en ambos casos sin cartelas. Asimismo, sin cartelas se exponían herramientas originales utilizadas en los trabajos forestales. Resultaban interesantes el despacho y el dormitorio de Francisco Mira, así como su cámara fotográfica, exhibida en una vitrina exenta en un lugar principal.

En la segunda planta, la casa mostraba - y lo sigue haciendo - el despacho del médico Luis Rivera (1913-2010), miembro de la familia que, con posterioridad, habitó el inmueble. En la azotea se encuentra un observatorio meteorológico.

La actual musealización reúne una importante colección de objetos que pertenecieron tanto a Francisco Mira como a los guardas forestales. Junto al abundante material gráfico y audiovisual, los textos explicativos completan una correcta musealización que no olvida hablar del territorio, contextualizando la repoblación tanto histórica como geográficamente. Entre otros apuntes que introduce, la exposición menciona -

\footnotetext{
${ }^{58}$ CANDELA, J. L'enginyer Mira i la pineda. En Guardamar del Segura. Arqueología y Museo. Alicante: Museo Arqueológico de Alicante, Ajuntament de Guardamar del Segura, Museo Arqueológico Guardamar del Segura, 2010, p. 230-245. Rocamora. Diseño y Arquitectura. [En línea]. <http://www.rocamoraarquitectura.es/home/casa-museo-ingeniero-mira-guardamar-museografia/>. [7 de abril de 2020].
} 
acertadamente - a "los grandes nombres de la historia contemporánea local: Belluga" Larramendi y Mira", aquellos que impulsaron actuaciones decisivas para configurar la comarca actual.

\section{Memorial de San Isidro}

Inaugurado en 2015, el Memorial de San Isidro surge como un museo diferente, una infraestructura cultural que pretende explicar la historia del municipio a partir de un discurso museológico que considera prioritaria la colaboración de la propia sociedad local. Junto a paneles con textos y fotografías en los que se describe, de manera contextualizada, la historia de la población, el centro exhibe una pequeña colección de piezas donadas por particulares, a los que se quiere involucrar en la andadura de este museo.

El memorial se ubica en una de las primeras viviendas que se edificaron en San Isidro, en concreto, en la destinada a los maestros, de forma que se trata de un museo "de sitio", pues utiliza como sede una de las casas originales del pueblo, rehabilitada para acoger este nuevo uso. Junto a ella, se ha recreado la marquesina y la fachada de la antigua estación del ferrocarril, que se encontraba en las inmediaciones de la localidad. El proyecto, impulsado desde el Ayuntamiento, se debe a la Cátedra Arzobispo Loazes, ya mencionada, de importante presencia en la zona.

San Isidro y El Realengo son los dos únicos pueblos levantados en los años cincuenta en la provincia de Alicante por el Instituto Nacional de Colonización (INC), organismo creado en 1939 con el fin de extender la superficie de regadío y crear poblaciones, instalando en ellos colonos formados en las nuevas técnicas hidráulicas. La actuación en ambos municipios fue diseñada a partir de la declaración de Zona de Interés Nacional (27 de junio de 1941) aplicada a los saladares de Albatera, Crevillente y Elche.

La construcción de El Realengo y San Isidro y la llegada de colonos fueron procesos que se llevaron a cabo a lo largo de la década de los cincuenta. San Isidro perteneció a Albatera, de la que consiguió segregarse en 1993. En la actualidad, su economía se orienta a la industria y, sobre todo, a los servicios. El Realengo, por su parte, pertenece a Crevillente (Bajo Vinalopó), municipio del que, últimamente, llegó a plantearse su segregación, pues sus vecinos no ocultan su malestar frente a los gestores del municipio del que dependen.

\section{Museo de La Alquería (Daya Nueva)}

En 2018 abrió al público el último - hasta el momento - de los museos de la comarca, situado en el municipio de Daya Nueva. Financiado por la Diputación e impulsado desde la Cátedra Arzobispo Loazes, el museo se ubica en la antigua casa del médico, rehabilitada para acoger este nuevo uso. Al utilizar un inmueble histórico de su entorno, el museo adquiere prestigio $\mathrm{y}$, probablemente, refuerza su presencia simbólica en la sociedad local. No es un caso aislado y, en la zona estudiada, hemos visto que abundan los ejemplos (Cox, Guardamar del Segura, Rojales o San Isidro, entre otros).

\footnotetext{
${ }^{59}$ Luis Belluga y Moncada (1662-1743) fundó los municipios de Dolores, San Fulgencio y San Felipe Neri, tras desecar amplias extensiones de terreno pantanoso en el tramo final del Segura. Véase: Real Academia de la Historia. [En línea]. <http://dbe.rah.es/biografias/8330/luis-belluga-y-moncada>. [18 de abril de 2020].
} 
"La Alquería" se ha formado gracias a donaciones de vecinos de la población, conformando, por tanto, un espacio - como otros museos de similar impronta - de doble lectura: sus fondos son, por un lado, heterogéneos, pues la población dona todo aquello que considera tan valioso como para poder deshacerse de ello - de su privacidad - y depositarlo en un museo, elevándolo a la categoría de público. Y, por otro, esos mismos fondos son una mimesis de los del museo del pueblo vecino, cuya población ha realizado el mismo trayecto hasta alcanzar el cenit de su identidad.

Este espacio, cuyo subtítulo reza "Centro de historia y cultura popular de Daya Nueva. Historia del pasado y presente de Daya Nueva para mirar al futuro", tiene página web en tres idiomas (castellano, valenciano e inglés), con abundante material gráfico y audiovisual, visita virtual, calendario de actividades y una selección de piezas referenciadas ${ }^{60}$. Entre las actividades que celebra destacan las conferencias, para lo cual se ha dotado de una pequeña sala en su piso superior. Al parecer, también consta de almacén, disponiendo, por tanto, de dos infraestructuras básicas en todo museo ${ }^{61}$.

Se trata, en definitiva, de un museo modesto que, no obstante, nace con pretensiones y pretende erigirse en un revulsivo para la población, tanto local como foránea, pues, como se afirmaba en la inauguración, "con este museo ampliamos la oferta cultural y turística de esta localidad y de la comarca" $"$.

\section{Centros de Visitantes de Parques Naturales}

Los centros de visitantes de los parques naturales o de cualesquiera otros espacios protegidos, son lugares en los que se explica el territorio que les rodea, introduciendo sus principales características. Obviamente, no se trata de museos, pues no basan su discurso en unos fondos conservados en sus salas, si bien, en ocasiones, exhiben pequeñas colecciones relacionadas con el entorno que presentan. En el Bajo Segura encontramos un solo parque natural, el de las lagunas de La Mata - Torrevieja ${ }^{63}$, en cuyo centro de visitantes - ubicado en una antigua casa forestal - se explican las características, principalmente naturales, de su entorno, priorizando el patrimonio que le ha llevado a su

\footnotetext{
${ }^{60}$ Museo Daya Nueva. [En línea]. <https://museodayanueva.es/index.php/es/>. [7 de abril de 2020].

${ }^{61}$ Diputación de Alicante. [En línea]. <http://www.diputacionalicante.es/abre-sus-puertas-el-nuevo-museode-daya-nueva-gracias-a-una-ayuda-de-la-diputacion-de-250-000-euros>. [7 de abril de 2020].

62 Ibidem.

${ }^{63}$ En la comarca hay reconocidos, además, un Paisaje Natural Protegido - la Sierra de Escalona y su entorno, que se extiende por Orihuela, Pilar de la Horadada y San Miguel de Salinas, espacio que, junto a la Dehesa de Campoamor, también se considera Lugar de Interés Comunitario -; cuatro Parajes Naturales Municipales (La Pilarica, en Callosa de Segura; las Lagunas de Lo Monte, en Pilar de la Horadada; la Sierra, en Redován - también Lugar de Interés Comunitario - y el Molino del Agua, en Torrevieja); ocho Lugares de Interés Comunitario (además de la Sierra de Escalona, ya mencionada, están los siguientes: la Cueva del Perro, en Cox; las Dunas de Guardamar, en Elche, Guardamar del Segura y San Fulgencio; el Litoral de Cabo Roig, la Rambla de las Estacas y la Sierra de Orihuela, en esta ciudad); la Sierra de Crevillente, que se extiende por las comarcas del Bajo y Medio Vinalopó, si bien penetra en los términos de Albatera y Orihuela; la Sierra de Callosa, en este municipio, Cox y Redován); y, al menos, quince microrreservas de flora. Un importante número de estos espacios se integra en la Red Natura 2000, considerados, además, como Zonas de Especial Protección para las Aves (ZEPA) y Zonas Especiales de Conservación (ZEC). Generalitat Valenciana. Conselleria de Agricultura, Desarrollo Rural, Emergencia Climática y Transición Ecológica. [En línea]. <http://www.agroambient.gva.es/es/web/biodiversidad/cartografia-de-microreservas-de-flora>. [7 de abril de 2020]. Generalitat Valenciana. Conselleria de Agricultura, Desarrollo Rural, Emergencia Climática y Transición Ecológica. [En línea]. <http://www.agroambient.gva.es/es/web/espacios-naturalesprotegidos>. [7 de abril de 2020].
} 
reconocimiento y protección; y descuidando - en nuestra opinión - la presencia humana en aquel, ofreciendo una visión sesgada del territorio, circunstancia no exclusiva de este parque. Aunque somos conscientes de que se trata de espacios naturales y que son estos valores los que se deben priorizar en unos centros, además, de reducidas dimensiones, no hay que olvidar la decisiva impronta humana en estas zonas a lo largo del tiempo, sin la cual no se explicarían sus características medioambientales.

\section{Centro de Interpretación del Parque Natural de las Lagunas de La Mata y Torrevieja}

Creado en 1994 y con una superficie superior a las tres mil quinientas hectáreas, el parque natural de las Lagunas de La Mata-Torrevieja conforma, junto a los de El Hondo y las Salinas de Santa Pola (Bajo Vinalopó), una importante zona de humedales al sur de Alicante. A su relevancia natural, este parque añade la histórica, al acoger una de las mayores explotaciones salineras de Europa. Asimismo, en este espacio se cultivan grandes extensiones de vid, cultivo prácticamente desaparecido en el Bajo Segura, con el que se elabora el conocido como "vino de La Mata".

En el centro de visitantes se introduce el territorio, principalmente en cuanto a sus valores naturales (flora, fauna). No obstante, la actividad antrópica también tiene su reflejo en su discurso, centrado en la obtención de la sal, el cultivo de la vid y los aprovechamientos de las plantas barrilleras y el esparto, de importancia secular en la zona. El planteamiento de este centro resulta interesante y, desde luego, superior al de otros cercanos, como analizaremos más adelante.

La obtención de sal en estas lagunas litorales se remonta a la Antigüedad, principalmente en la de La Mata, que se caracterizaría "por tener la hegemonía productiva frente a la[s] de Torrevieja hasta el comienzo del siglo XIX" "64. A finales del XVIII, Torrevieja ya había iniciado su actividad salinera, reflejada, como hemos visto, por Cavanilles. En efecto, desde el último cuarto del setecientos, la laguna de Torrevieja - antiguamente denominada albufera de Orihuela - se orientó hacia esta explotación, cuyo monopolio recaía en la Corona $^{65}$. Junto a una torre, unas eras y un embarcadero, nació un núcleo urbano - germen de la actual Torrevieja - que fue poblándose con gentes procedentes de áreas limítrofes, como el Campo de Salinas o el de Cartagena ${ }^{66}$. Factores como, entre otros, la calidad de la sal y las mejores condiciones que ofrecía su rada, reforzaron la explotación en Torrevieja, relegando a un segundo plano el trabajo en La Mata.

En el primer tercio del XX, la instalación de lavaderos mecánicos o el uso del ferrocarril para transportar la sal hasta las eras, dieron lugar a un incremento de la producción, hecho que repercutió en el territorio circundante. En fechas recientes, la ampliación del puerto y la construcción de un salmueroducto procedente del municipio de Pinoso, han convertido a las salinas de Torrevieja en las de mayor producción en Europa ${ }^{67}$.

\footnotetext{
${ }^{64} \mathrm{MUÑOZ}, \mathrm{R}$. De La Marquesa a Los Montesinos. El fracaso de una colonización planificada frente al éxito de un asentamiento espontáneo que logra ser municipio (siglos XVIII al XX). Los Montesinos: Ayuntamiento de Los Montesinos, 2013, p. 37.

${ }^{65}$ Ibidem, p. 40.

${ }^{66}$ Ibidem, p. 263.

${ }^{67}$ Salinas de Torrevieja. [En línea]. <http://www.visitasalinasdetorrevieja.com/sitio-excepcional/>. [7 de abril de 2020].
} 
La explotación salinera está indisolublemente unida al origen mismo de Torrevieja. Determinadas infraestructuras vinculadas a esta actividad también forman parte de la historia de la población, como las antiguas eras de la sal, donde se celebra el certamen de habaneras y polifonía de la ciudad. Por otro lado, embarcaciones como el pailebote Pascual Flores - del que ya nos hemos hecho eco en el presente artículo - también está estrechamente vinculado a la actividad mercantil desarrollada en el municipio.

En definitiva, dada la importancia histórica de la sal en el entorno del parque natural de las lagunas de La Mata - Torrevieja, consideramos que su centro de interpretación debería reforzar la presencia de aquella en su discurso. Y esto pese a la existencia en el municipio de un centro específico sobre la industria salinera ${ }^{68}$, centro que, al menos desde 2015 , permanece cerrado ${ }^{69}$.

A modo de ejemplo, veamos qué ocurre en los cercanos enclaves de El Hondo y las Salinas de Santa Pola, estrechamente vinculados al analizado y donde encontramos dos planteamientos opuestos. Sobresalen, por un lado, las prolijas explicaciones que se ofrecen en el centro de visitantes "Museo de la Sal", en el vecino municipio de Santa Pola, espacio que basa su discurso en la importancia de la sal como producto y en las actividades que a lo largo de la historia el ser humano ha llevado a cabo para obtenerla. Todo ello adecuadamente contextualizado en la zona, de la que describe su historia, intervención antrópica responsable de su supervivencia. Dado que el centro de visitantes se encuentra situado en una instalación industrial -antiguo molino salinero-, el propio edificio sufrió un proceso de adaptación que puso en valor su arquitectura y su carácter funcional.

Por otro lado, nos encontramos con el centro de El Hondo, paraje constituido, principalmente, por dos grandes embalses construidos por Riegos de Levante en la década de los cuarenta del siglo XX. Los embalses se construyeron en un área pantanosa como reservorios de agua de esta empresa, que contaba con importantes concesiones, tanto del Segura como de algunos de sus azarbes y que, en la actualidad, irriga miles de hectáreas ${ }^{70}$. Por tanto, el Hondo es también un espacio antrópico, pues es la actividad humana en la zona la que ha permitido, construyendo tales infraestructuras, la creación de un rico ecosistema. Al tratarse de un importante espacio protegido - como los demás parques citados -, se encuentra sometido a diferentes directivas europeas, ya citadas (ZEPA desde 1989; LIC, desde 2006, entre otras) $)^{71}$ y dispone de personal técnico responsable de su gestión, que asume tareas de conservación, investigación y difusión, gestionadas desde la

\footnotetext{
${ }^{68}$ Torrevieja.com. [En línea]. <https://torrevieja.com/centro-de-interpretacion-de-la-industria-salinera/> . [8 de abril de 2020].

${ }^{69}$ Creado, al parecer, en 2002, este espacio se ubica en un muelle de mercancías - rehabilitado - de la antigua estación de trenes de Torrevieja (línea Albatera-Torrevieja, clausurada en 1985). Estaba previsto que la visita a este centro se llevara a cabo junto a un recorrido por las salinas, realizado por un tren turístico que, puesto en marcha hace unos años, en el momento de redactar estas líneas no funciona, debido a los efectos ocasionados por los temporales de 2019 y 2020, que anegaron parte del trazado por el que discurría. Información. [En línea]. <http://www.diarioinformacion.com/vega-baja/2012/08/28/rincon-historiasalinera/1288519.html>. [8 de abril de 2020]. LÓPEZ, A. y ROSSELLÓ, V.M. Geografía de la Provincia de Alicante. Alicante: Excma. Diputación Provincial de Alicante, 1978, p. 354.

${ }^{70}$ Riegos de Levante. Comunidad General de Regantes. [En línea]. <https://riegosdelevante.es/rlevante/historia/>. [8 de abril de 2020].

${ }^{71}$ Generalitat Valenciana. Conselleria de Agricultura, Desarrollo Rural, Emergencia Climática y Transición Ecológica. [En línea]. <http://www.parquesnaturales.gva.es/es/web/pn-el-fondo/conocenos>. [8 de abril de 2020].
} 
Conselleria de la cual depende. No obstante, su centro de interpretación no hace mención alguna a esta dilatada historia, sino que basa su discurso en la riqueza biológica del enclave. Tan solo exhibe un panel titulado "El hombre y su tierra", en el que se reproducen algunas fotografías, en su mayor parte pertenecientes a la colección conservada en el cercano Museo Escolar de Puçol (Elche). En ellas se muestran actividades tradicionales del entorno del parque, como el encaperuzado o la venta de palmas, el hilado de cáñamo o el arado con vacas, entre otras. Pero nada se dice del origen antrópico de los embalses reguladores que dieron origen al paraje actual ni lo que supuso el riego por elevación en las comarcas del sur valenciano. No se habla de su propia génesis como espacio, pero tampoco de la rica historia de la zona, huérfana de referencias - excepción sea hecha de la Casa-Museo del Ingeniero Mira - a las desecaciones llevadas a cabo por el cardenal Belluga en el siglo XVIII, ya mencionado. En un entorno tan complejo como el inmediato a este parque (y al resto de humedales del sur alicantino), explicar adecuadamente, in situ, estos temas, se convierte en una cuestión esencial.

Para finalizar, en los discursos expositivos de los centros de interpretación se echa en falta, en general, una mayor crítica, que sí encontramos, por otro lado, en las respectivas páginas webs: factores como la contaminación del agua, la presión urbanística o la afluencia de turistas, entre otros - problemáticas diversas, fruto de una miope percepción utilitarista del enclave y no de una respetuosa cultura del territorio -, son ausencias destacables en unas salas que deben introducir en toda su dimensión geográfica el entorno que presentan.

En este sentido, las recientes actividades desarrolladas en áreas limítrofes de los parques mencionados, persiguen poner de manifiesto la riqueza patrimonial de la zona (cultura, naturaleza...) y su relevancia turística, con el fin de diversificar los usos del entorno y potenciar su mantenimiento y supervivencia. No obstante, la misma población local que otorga su beneplácito a todas aquellas iniciativas centradas principalmente en la difusión (romerías, trenes turísticos, caza, visitas guiadas...), a menudo se opone a medidas proteccionistas hacia el medio, hecho que nos lleva a considerar que no estamos ante un cambio de tendencia en la gestión de estos espacios y su entorno inmediato.

\section{CONCLUSIONES Y PROPUESTAS}

Como hemos tenido ocasión de comprobar en las líneas que anteceden, nos encontramos ante espacios modestos, no reconocidos en su mayoría y, dada la escasez de medios de que adolecen, imposibilitados para desarrollar las funciones esenciales de todo museo, aun considerando - como se ha dicho - que no revisten esta categoría y que, a menudo, encontramos en ellos fuertes dosis de voluntarismo. No obstante, que muchos de estos centros no consten como museos o colecciones porque la administración no los reconozca como tales, no los exime de cumplir un protocolo de actuaciones que consideramos necesario.

También se argumentaba al inicio de este artículo que esta situación no solo era debida a su escasez presupuestaria - hecho que, entre otras cuestiones, impide la presencia de un equipo técnico estable y competente en sus instalaciones -, sino al discurso previo que impregna la práctica totalidad de estos espacios. Consideramos que este trabajo ha puesto de manifiesto que, si bien resulta positiva la conservación del patrimonio - en un sentido amplio - y el esfuerzo por visibilizarlo que se ha llevado a cabo en los últimos años, los 
museos creados no reúnen - en general - los requisitos mínimos exigibles que debería cumplir cualquier institución de estas características. Así, brevemente enunciado, sostenemos que las funciones de exposición, difusión e investigación adolecen de importantes carencias, como desarrollamos a continuación.

Para comenzar, la práctica totalidad de estos espacios carece de proyecto museológico y museográfico, y tampoco se dispone de planes estratégicos o directores específicos. Al parecer, no se planifica qué se va a exhibir ni de qué manera, o esta planificación se lleva a cabo superficialmente; y, en la medida en que estos centros muestran al público su historia y su entorno, es ese mensaje el que se debe cuidar, so pena de ofrecer una visión, en nuestra opinión, distorsionada de la realidad. La programación de un museo debe realizarse en función de unas colecciones ${ }^{72}$ y los museos de etnografía, aquellos que conservan patrimonio relacionado con las sociedades tradicionales (preindustriales) o en vías de transformación, deberían de exhibir fondos que reflejaran de manera fidedigna el pasado de un espacio y de una sociedad concreta, tras desarrollar las investigaciones y estudios pertinentes. Por su parte, los museos de nuestra zona de estudio, a menudo se nutren de colecciones conformadas por asociaciones o particulares, origen no ceñido a criterios científicos. No obstante, hay que reconocer el empuje de la sociedad civil comarcal en aras de la conservación de su patrimonio pues, como hemos visto, menudean los museos creados con fondos procedentes de colectivos, que también velan por el mantenimiento y la difusión de sus tradiciones. Junto a las asociaciones que aparecen a lo largo del texto, debemos mencionar también a la peña "Los Santicos de la Piedra", de Almoradí y a la barraca "La Gramaera", de Redován"

En los espacios estudiados encontramos discursos miméticos, fruto de la falta de trabajo en común y de la ausencia de una política museística de mayor alcance. A modo de ejemplo, en un entorno cercano nos hallamos, al menos, ante cuatro o cinco museos de la huerta (en Callosa de Segura, Cox, Daya Nueva, Dolores y Rojales), espacios que repiten colecciones - desequilibradas -, con las que cada población muestra su identidad, idéntica a la del pueblo vecino y haciendo buena la máxima coloquial que afirma que "se exhibe lo que hay". Como se ha mencionado, la inexistencia de un proyecto intelectual previo que, entre otras funciones, inventaríe y documente las colecciones, lastra la marcha de estas iniciativas, sobre las que, además, se ciernen importantes "olvidos" de carácter geográfico.

El "rescate" de la identidad discrimina entornos y actividades y, en este sentido, consideramos que las sierras y los secanos - el campo - son los grandes olvidados, aun reconociendo la impronta que el espacio huertano ejerce en la comarca, con la que se identifica: arquitectura de piedra en seco, eras, canteras, acequias, minas, hornos de cal, presas... son muestras, entre otras, de un patrimonio sobre el que se cierne la amenaza de

\footnotetext{
${ }^{72}$ HERNÁNDEZ, F. Manual de Museología. Madrid: Editorial Síntesis, 1994, p. 121.

${ }^{73}$ La peña huertana "Los Santicos de la Piedra" se creó en 1996, con el objetivo de dar a conocer las tradiciones del municipio y de la comarca. Realizan diferentes actos a lo largo del año, si bien se muestran excepcionalmente activos con motivo de las fiestas de la localidad, cuando, entre otras actividades, recrean una barraca tradicional en la vía pública. Información. [En línea]. <https://www.diarioinformacion.com/vega-baja/2010/07/23/manana-abre-barraca-museo-penahuertana/1029286.html>. [20 de abril de 2020]. Por otro lado, la Asociación Cultural y Festera "La Gramaera" se creó en 1977 y desde 1980 realiza una exhibición de grama e hilado del cáñamo con motivo de las fiestas patronales de Redován. Activa. Orihuela. Vega Baja. [En línea]. $<$ https://www.activaorihuela.es/la-gramaera-organiza-trigesimo-septima-exhibicion-grama-e-hilado-delcanamo-este-domingo-las-fiestas-redovan/>. [20 de abril de 2020].
} 
su desaparición. Otras manifestaciones culturales de la comarca, ausentes casi por completo de cualquier iniciativa museística existente en ella, son - sin ánimo de exhaustividad - la colombicultura, la apicultura, la sericicultura, la minería o el folclore musical, saberes, destrezas o conocimientos ajenos, hasta ahora, de los museos del Bajo Segura, cuya memoria los discrimina y no parece reconocer en ellos su carácter tradicional e identitario.

Sin líneas de actuación trazadas con rigor, los museos existentes en nuestra zona de estudio se ciñen, en general, a una dinámica similar: en primer lugar, la exposición es convencional, con riesgo de resultar acientífica, habida cuenta de la ausencia de un trabajo previo de inventario y documentación. A menudo nos encontramos con exposiciones abigarradas, entre otras causas, debido - junto a la falta de criterio - a la escasez de equipamientos (almacenes, etc.). Por otro lado, tampoco se llevan a cabo las tareas esenciales que deben realizarse en todo museo (conservación, difusión e investigación); escasea el material impreso publicitario ${ }^{74}$, si bien las páginas webs municipales sí suelen recoger información al respecto.

La ausencia de programación repercute negativamente en la museografía de la práctica totalidad de estos museos, que no tiene en cuenta aspectos decisivos para su buen funcionamiento, tales como la distribución de los espacios o la integración de los sistemas de climatización, seguridad e iluminación, equipamientos precarios que van en detrimento de la conservación de las piezas. En cuanto a las condiciones de accesibilidad, los museos situados en edificios nuevos o rehabilitados sí suelen cumplir con la normativa, extremo este imposible de alcanzar en aquellos otros que ocupan inmuebles históricos, circunstancia que, no obstante, les otorga valor añadido.

Estos museos tienen una serie de condicionantes, como el horario de apertura al público o la escasez de personal, por citar solo algunas cuestiones de una problemática más compleja. Prácticamente, no se elabora material didáctico alguno y la traducción de cartelas y textos a diversos idiomas continúa siendo un tema pendiente. En resumen, el punto de partida (y posterior desarrollo) que encontramos en la gestación de la mayoría de museos de la zona no se ajusta a ningún protocolo de actuación. Escasea, asimismo, el personal técnico adscrito a estos centros y, con frecuencia, un único responsable asume varias competencias municipales. Por otro lado, algunos de los museos se gestionan desde las áreas de turismo de sus respectivos municipios. Sin menoscabo del trabajo desarrollado por cualesquiera otros profesionales, consideramos que es necesaria la presencia en los museos de personal técnico específicamente formado en temas patrimoniales (arqueología, historia...) - no solo en su difusión o interpretación -, trabajando conjuntamente con el resto del personal adscrito.

Si bien es cierto que la precariedad de medios humanos y materiales constriñe el funcionamiento de estos centros, ello no debe justificar, únicamente, sus carencias, basadas en el desconocimiento de las actividades que definen a los museos o colecciones. Consideramos que la falta de proyectos museológicos interdisciplinares y específicos condena la marcha de estos espacios que, en general, fueron creados en un contexto de improvisación y escaso rigor. Se constata, por tanto, su funcionamiento deficiente, cuyas características, comunes, se resumen a continuación:

\footnotetext{
${ }^{74}$ Excepto en Guardamar del Segura, Orihuela o Torrevieja, los municipios más turísticos de la comarca.
} 
- Inexistencia de programación. Improvisación, falta de rigor, desconocimiento de las funciones que debe cumplir un museo.

- Discrecionalidad y falta de profesionalidad en relación a la gestión de contenidos. ¿Quién decide - y en función de qué - las tradiciones de un lugar o aquello que define y representa al entorno?

- Escasez de personal, con falta de técnicos y predominio de los cargos subalternos, sin formación adecuada.

- Horarios de apertura discrecionales y, a menudo, confusos, hecho que va en detrimento de una adecuada difusión, esta asimismo precaria.

- Escasez de actividades, sobre todo, las didácticas.

- Débil presencia en la Web.

- Práctica inexistencia de investigación. Tan solo en relación a algunos museos (Pilar de la Horadada, Rojales...) encontramos publicaciones alusivas a la historia y al patrimonio local, elaboradas por personal técnico vinculado a estos centros u otros profesionales.

A pesar de esta visión general, en nuestra opinión algunos museos sobresalen por su trayectoria y características. Nos referimos, principalmente, al museo arqueológico de Guardamar, al del cáñamo de Callosa de Segura o al de la huerta de Rojales, centros desde los cuales se realizan determinadas funciones, sobre todo de carácter divulgativo, si bien en la mayor parte de ellos queda pendiente - como en el resto - acometer adecuadamente la documentación, conservación y exhibición de sus respectivas colecciones. Para ver resultados diferentes en los nuevos espacios de Daya Nueva y San Isidro, que irrumpen con fuerza en el panorama cultural de la comarca, habrá que esperar. Al margen de esta situación, debemos mencionar las actividades educativas y de difusión que se desarrollan en los centros de visitantes de los parques naturales, que sí disponen de personal técnico a su cargo.

Por otro lado, en los últimos años, varios municipios de la comarca han comenzado a ofertar, también desde las páginas webs de sus respectivos ayuntamientos, diferentes itinerarios a lo largo de su término municipal, rutas que divulgan el patrimonio natural o cultural de su entorno. Junto a las ya mencionadas (en Cox, Dolores, Guardamar del Segura, Pilar de la Horadada o Rojales, entre otros), resultan interesantes - sin ánimo de exhaustividad - las propuestas de Almoradí, Orihuela, Redován o Torrevieja, poblaciones que dan a conocer ermitas, áreas recreativas, miradores, huertas, "vías ferratas", etc., configurando un escenario que irá a más en el futuro ${ }^{75}$.

Para finalizar, a partir de los años ochenta, la explosión museística que se vivirá en España, irá abriéndose paso - de manera transversal - junto a una nueva generación de museos, aquella que suple con medios audiovisuales y estrategias de simulación su inexistente colección. En los últimos años, en efecto, se asiste a importantes transformaciones en el seno de la museología. Sostenemos, con Gregori, que, por un lado, ha ido surgiendo una especialización de la oferta museística, fenómeno que, por su propia naturaleza, continúa ofreciendo gran dinamismo. Lo "museable" se ha extendido a

\footnotetext{
75 Ayuntamiento de Almoradí. [En línea]. <http://www.almoradi.es/2017/04/11/sotos/>. [21 de abril de 2020]. Ayuntamiento de Orihuela. [En línea]. <http://www.orihuela.es/via-publica-medio-ambiente-yterritorio/desarrollo-rural/orihuela-en-ruta/>. [21 de abril de 2020]. Ayuntamiento de Redován. [En línea]. <http://www.redovan.es/turismo/turismo-activo/>. [21 de abril de 2020]. Ayuntamiento de Torrevieja. [En línea]. <http://www.torrevieja.es/sal/Torrevieja/Rutas/Ruta\%20marinera/Indice\%20ruta\%20marinera/>. [21 de abril de 2020].
} 
objetos y colecciones de diversa naturaleza, algunas alejadas de las tradicionales clasificaciones académicas, situación que debe relacionarse con la ampliación del concepto de patrimonio, progresivamente enriquecido con la inclusión de aquellos bienes que una sociedad, asimismo, más formada, valora y pretende proteger ${ }^{76}$.

En segundo lugar, el propio museo, anteponiendo el fin a los medios, desdibuja su identidad y, en ocasiones, bajo esa denominación surgen instituciones distintas que pueden no reunir los requisitos de aquel ${ }^{77}$. Frente al museo considerado "clásico", donde "cada sala era concebida como la etapa transitiva de una información reglada, que, a través de una visión sintética de todas las obras reunidas, aspiraba a dispensar un panorama integral, una instrucción completa"78, asistimos a la creación de nuevos museos, algunos de ellos producto de colecciones particulares, que se pretenden rentabilizar como producto de consumo.

En contraposición a la museología tradicional (que se reduce a meras colecciones de objetos, cuya funcionalidad última recae en el estudio académico de sus contenidos y, por tanto, solo son accesibles a los iniciados en la disciplina representada), la interacción actual de la sociedad, no ya solo en las colecciones sino en todo lo que representa la actividad de los museos, se ha convertido en prioritaria, resultado de las transformaciones sociales experimentadas en las últimas décadas. Asimismo, en palabras de Bolaños, el museo se somete a una profunda revisión y se cuestiona "su capacidad para hacerse comprender, su finalidad social, su funcionamiento interno, su proyección pública; en definitiva, todas sus dimensiones, hasta alcanzar su autenticidad y la necesidad de su misma existencia"79.

En nuestra opinión, esta nueva museología se encuentra ausente de los museos analizados, que basan su mensaje en la nostalgia, sentimiento que, si bien nos puede acercar al pasado, a menudo lo hace de forma acrítica, mostrándose incapaz de generar un planteamiento comprometido con el presente. El recurso a la nostalgia muestra un pasado idealizado y atemporal, separado de la actualidad, con la que rompe los lazos. La práctica totalidad de los museos evocan un pasado fijo e inerte, refugio para un público mayoritariamente local que ansía tener bajo llave un santuario para su identidad.

No se muestra como debiera el continuo espacio-tiempo de las sociedades y el resultado es un remanso de paz, una cultura pura o un territorio virgen (sic); una arcadia feliz, con frecuencia ajena a la crítica, a la reflexión y al compromiso con nuestra época. Son museos pensados para la mera contemplación autocomplaciente y ausente de análisis, pues no se relacionan con la realidad actual del entorno en el que surgen, como si la geografía y la historia, el propio "pueblo", no fueran un constante ir haciéndose. Y estos museos - todos - deben de ser algo más; una herramienta cuando menos capaz de cambiar a la sociedad, de hacerla crecer, extremo este harto difícil de continuar ofreciendo un mensaje incapaz de recorrer en toda su amplitud la línea argumental que lo une a nuestros días. Al hacerlo así, se corre el riesgo de mostrar un pasado lejano, en cuyo devenir parece no haber existido responsables. En términos coloquiales, si los museos - en general -

\footnotetext{
${ }^{76}$ GREGORI, J., op.cit., p. 97 y 99.

${ }^{77}$ Ibidem.

${ }^{78}$ BOLAÑOS, M. Historia de los museos en España. Memoria, cultura, sociedad. Gijón: Ediciones Trea, 1997, p. 430.

${ }^{79}$ Ibidem, p. 427.
} 
"sirven para algo", esta forma de educar y de generar capacidad de reflexión y debate no debieran descuidarse.

La modernidad y la homogeneidad de las sociedades contemporáneas se extiende a, prácticamente, todos los "lugares". Como una suerte de reacción defensiva ante la anulación de lo local, surgen fenómenos identitarios que valorizan lo propio, sentimientos bien manejados por una clase política avispada y atenta a glorias efímeras. La proliferación de hechos diferenciales viene de la mano de esa reacción identitaria que pretende no sucumbir ante la marea homogénea de la sociedad capitalista postindustrial.

En las últimas décadas el museo crece y se renueva conceptualmente; su número e importancia simbólica aumenta, hecho que no debe ocultar los problemas a los que debe hacer frente: carácter espontáneo y discrecionalidad en cuanto a su creación, sometida a vaivenes políticos; escasez de medios humanos y materiales, unida a la falta de ideas y proyectos elaborados con rigor, entre otros. Estas carencias observadas en los museos resultan todavía más gravosas al considerar que la democratización cultural y la ampliación de lo museable los convierten en un recurso a potenciar ${ }^{80}$.

\section{BIBLIOGRAFÍA}

ALBERT, R. F. La industria del cáñamo en Callosa de Segura (Alicante). Catalogación y estudio de utillajes y otros productos derivados de esta industria artesanal. Alicante: Instituto de Cultura «Juan Gil-Albert», Diputación Provincial de Alicante, 1989. 232 p.

BAUMAN, Z. Vida líquida. Barcelona: Ediciones Paidós, 2019. 206 p

BOLAÑOS, M. Historia de los museos en España. Memoria, cultura, sociedad. Gijón: Ediciones Trea, 1997. 512 p.

BROTONS, B. y SOLER, A. S'ha perdut una cultura del Camp d'Elx. Elche: Caja de Ahorros de Alicante y Murcia, 1986. 104 p.

CANAlES, G. El Bajo Segura. En UROZ, J. Historia de la Provincia de Alicante. Murcia: Ediciones Mediterráneo, 1985, vol. I², p. 371-435.

CANALES, G. El Bajo Segura. Estructura espacial, demográfica y económica. Alicante: Cam Fundación Cultural, Universidad de Alicante, 1995. 312 p.

CANALES, G. La catástrofe sísmica de 1829 y sus repercusiones. Almoradí: Excma. Diputación Provincial de Alicante, Excmo. Ayuntamiento de Almoradí, Universidad de Alicante, 1999. 353 p.

CANALES, G. y RUÍZ, E. La Huerta del Bajo Segura (Alicante), un patrimonio cultural en peligro. Reflexiones sobre un proyecto museológico integral. Investigaciones Geográficas, 2011, nº 54, p. 204-248.

\footnotetext{
${ }^{80}$ Ibidem, p. 434
} 
CANDELA, J. L'enginyer Mira i la pineda. En Guardamar del Segura. Arqueología y Museo. Alicante: Museo Arqueológico de Alicante, Ajuntament de Guardamar del Segura, Museo Arqueológico Guardamar del Segura, 2010, p. 230-245.

DE GEA, M. La construcción del paisaje agrario en el Bajo Segura. De los orígenes hasta la implantación de la red de riego-drenaje principal en el alfoz oriolano. Alquibla. Revista de Investigación del Bajo Segura, 1995, nº 1, p. 65-100.

DE GEA, M. La formación y expansión decisiva de la huerta de Murcia-Orihuela: un enfoque desde la perspectiva de la Orihuela musulmana (siglos VIII - XIII). Alquibla. Revista de Investigación del Bajo Segura, 1997, n 3, p. 155-217.

DE GEA, M. Los regadíos de la huerta histórica de Orihuela. En FERRÁNDEZ, T. y DIZ, E. Historia Natural de la Huerta de Orihuela. Orihuela: Ayuntamiento de Orihuela, 2015, p. 215-249.

DIZ, E. Poblamiento y usos tradicionales en la Sierra de Orihuela. En: MARTÍNEZ, S. y FERRÁNDEZ, T. Historia Natural de la Sierra de Orihuela. Orihuela: Ayuntamiento de Orihuela, 2011, p. 75-94.

GARCÍA, M. Arroz con leche: homenaje a los protagonistas de las duras décadas de los años 40 y 50 en Pilar de la Horadada. Pilar de la Horadada: Ayuntamiento de Pilar de la Horadada, 2003. 324 p.

GARCÍA, M. El desfile de carrozas de Pilar de la Horadada: Una manifestación cultural. Pilar de la Horadada: Ayuntamiento de Pilar de la Horadada, 2014. 208 p.

GIL, A. y CANALES, G. Residuos de propiedad señorial en España. Perduración y ocaso en el Bajo Segura. Alicante: Universidad de Alicante, 2007. 504 p.

GRAU, I. y MORATALLA, J. El campo y la agricultura. En Iberia, Hispania, Spania. Una mirada desde Ilici, Alicante: Caja de Ahorros del Mediterráneo, 2004, p. 119-124.

GREGORI, J. Per què uns museus d'etnologia en l'entorn alacantí? Canelobre. Revista del Instituto Alicantino de Cultura «Juan Gil-Albert», 2000, n 41/42, p. 97-116.

HERNÁNDEZ, F. Manual de Museología. Madrid: Editorial Síntesis, 1994. 318 p.

LACARRA, J., SÁNCHEZ, X. y JARQUE, F. Las Observaciones de Cavanilles. Doscientos años después. Valencia: Fundación Bancaja, vol 4, 1997. 512 p.

LÓPEZ, A. y ROSSELlÓ, V. M. Geografía de la Provincia de Alicante. Alicante: Excma. Diputación Provincial de Alicante, 1978. 615 p.

MARTÍNEZ, R. El molino hidráulico de Formentera. Un patrimonio etnológico en peligro. Alquibla. Revista de Investigación del Bajo Segura, 1999, nº 5, p. 505-519.

MARTÍNEZ, R. Museos que flotan. La Verdad, n 34.660, 6 de septiembre de 2012, p. 19. 
MUÑOZ, R. De La Marquesa a Los Montesinos. El fracaso de una colonización planificada frente al éxito de un asentamiento espontáneo que logra ser municipio (siglos XVIII al XX). Los Montesinos: Ayuntamiento de Los Montesinos, 2013. 471 p.

NOGUÉ, J. Cartografía de los cambios sociales y culturales. En ROMERO, J. Geografía Humana. 2a ed. Barcelona: Editorial Ariel, 2007, p. 173-219.

VERA, J. F. Tradición y cambio en el campo del Bajo Segura. Alicante: Instituto de Estudios Alicantinos, Diputación Provincial de Alicante, 1984. 219 p.

\section{RECURSOS ELECTRÓNICOS}

Activa. Orihuela. Vega Baja. [En línea]. <https://www.activaorihuela.es/la-gramaeraorganiza-trigesimo-septima-exhibicion-grama-e-hilado-del-canamo-este-domingo-lasfiestas-redovan/>. [20 de abril de 2020].

ADAMACO. Asociación de Amigos del Museo Arqueológico Comarcal de Orihuela. [En línea]. <https://www.facebook.com/adamacorihuela/?_tn_=\%2Cd\%2CPR\&eid=ARBpJgZFywni_UIDRWUO2vTYki0cs_5xVceqFCFGYQmcmTCm3f46fi4D0GFt048AdzDw-AYKy5EKTxn>. [14 de abril de 2020].

Almazara del Tío José María. [En línea]. <https://www.gluseum.com/ES/LaAparecida/284203421747865/Almazara-del-t\%C3\%ADo-Jos\%C3\%A9-

Mar\%C3\%ADa>. [7 de abril de 2020].

Ayuntamiento de Almoradí. [En línea]. <http://www.almoradi.es/2017/04/11/sotos/>. [21 de abril de 2020].

Ayuntamiento de Cox. [En línea]. <http://www.cox.es/el-municipio/turismo/museos/>. [6 de abril de 2020].

Ayuntamiento de Dolores. [En línea]. <http://www.dolores.es/coleccion-museograficamuseo-de-la-huerta/>. [6 de abril de 2020].

Ayuntamiento de Dolores. [En línea]. <http://www.dolores.es/ruta-ornitologica-por-lahuerta-de-dolores-y-el-parque-natural-el-hondo/>. [7 de abril de 2020].

Ayuntamiento de Formentera del Segura. [En línea]. <http://www.formenteradelsegura.es/turismo/folletos-turisticos/>. [25 de abril de 2020].

Ayuntamiento de Formentera del Segura. [En línea]. <http://www.formenteradelsegura.es/turismo/que-ver-que-visitar-quedisfrutar/patrimonio-artistico-cultural/molino-hidraulico-harinero/>. [7 de abril de 2020].

Ayuntamiento de Orihuela. [En línea]. <http://www.orihuela.es/via-publica-medioambiente-y-territorio/desarrollo-rural/orihuela-en-ruta/>. [21 de abril de 2020].

Ayuntamiento de Pilar de la Horadada. [En línea]. <http://www.pilardelahoradada.org/areas/cultura/museo>. [6 de abril de 2020].

Ayuntamiento Pilar de la Horadada. [En línea]. <http://www.visitpilardelahoradada.com/es/que_ver_hacer/rutas>. [16 de abril de 2020].

Ayuntamiento de Redován. [En línea]. <http://www.redovan.es/turismo/turismo-activo/>. [21 de abril de 2020]. 
Ayuntamiento de Rojales. [En línea]. <http://www.rojales.es/museo-de-la-huerta/>. [7 de abril de 2020].

Ayuntamiento de Torrevieja. [En línea]. <http://www.torrevieja.es/sal/Torrevieja/Rutas/Ruta\%20marinera/Indice\%20ruta\%20m arinera/>. [21 de abril de 2020].

Diputación de Alicante. [En línea]. <http://www.diputacionalicante.es/abre-sus-puertasel-nuevo-museo-de-daya-nueva-gracias-a-una-ayuda-de-la-diputacion-de-250-000euros>. [7 de abril de 2020].

Generalitat Valenciana. Conselleria de Agricultura, Desarrollo Rural, Emergencia Climática $y$ Transición Ecológica. [En línea]. <http://www.agroambient.gva.es/es/web/biodiversidad/cartografia-de-microreservas-deflora>. [7 de abril de 2020].

Generalitat Valenciana. Conselleria de Agricultura, Desarrollo Rural, Emergencia Climática $y$ Transición Ecológica. [En línea]. <http://www.agroambient.gva.es/es/web/espacios-naturales-protegidos>. [7 de abril de 2020].

Generalitat Valenciana. Conselleria de Agricultura, Desarrollo Rural, Emergencia

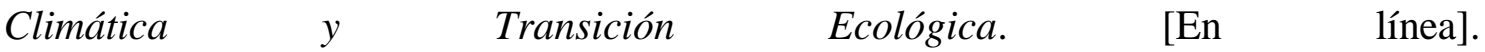
<http://www.parquesnaturales.gva.es/es/web/pn-el-fondo/conocenos>. [8 de abril de 2020].

Generalitat Valenciana. Conselleria de Educación, Cultura y Deporte. [En línea]. <http://www.ceice.gva.es/es/web/patrimonio-cultural-y-museos/etnologia>. [2 de abril de 2020].

Generalitat Valenciana. Conselleria de Educación, Cultura y Deporte. [En línea]. <http://www.ceice.gva.es/es/web/patrimonio-cultural-y-museos/inventario-general>. [9 de abril de 2020].

Granada Mollar de Elche. [En línea]. <http://www.granadaselche.com/granada>. [7 de abril de 2020].

Información. [En línea]. <https://www.diarioinformacion.com/vegabaja/2018/12/20/almoradi-adquiere-primera-vivienda-social/2099614.html > . [14 de abril de 2020].

Información. [En línea]. <http://www.diarioinformacion.com/vegabaja/2013/03/10/capricho-46-millones-dique-muerto/1351989.html>. [7 de abril de 2020].

Información. [En línea]. <https://www.diarioinformacion.com/vegabaja/2017/05/30/granja-cox-estrenan-ruta-huerta/1900100.html> . [6 de abril de 2020].

Información. [En línea]. <https://www.diarioinformacion.com/vegabaja/2010/07/23/manana-abre-barraca-museo-pena-huertana/1029286.html>. $[20$ de abril de 2020].

Información. [En línea]. <https://www.diarioinformacion.com/vegabaja/2017/02/16/nuevo-mirador-hiladores-canamo-costara/1861078.html >. [2 de abril de 2020]. 
Información. [En línea]. <http://www.diarioinformacion.com/vegabaja/2012/08/28/rincon-historia-salinera/1288519.html>. [7 de abril de 2020].

Ley 16/1985, de 25 de junio, del Patrimonio Histórico Español. [En línea]. <https://www.boe.es/eli/es/1/1985/06/25/16/con>. [2 de abril de 2020].

Museo Daya Nueva. [En línea]. <https://museodayanueva.es/index.php/es/>. [7 de abril de 2020].

Museos de Rojales. [En línea]. <http://museosderojales.es/museo-de-la-huerta/>. [7 de abril de 2020].

Real Academia Española. [En línea]. 〈https://dle.rae.es/etno->. [1 de abril de 2020].

Real Academia de la Historia. [En línea]. <http://dbe.rah.es/biografias/8330/luis-bellugay-moncada>. [18 de abril de 2020].

Repositorio Institucional de la Universidad de Alicante. [En línea]. <http://rua.ua.es/dspace/handle/10045/77432>. [21 de abril de 2020].

Riegos de Levante. Comunidad General de Regantes. [En línea]. <https://riegosdelevante.es/rlevante/historia/>. [8 de abril de 2020].

Rocamora. Diseño $\quad y \quad$ Arquitectura. [En línea]. $<$ http://www.rocamoraarquitectura.es/home/casa-museo-ingeniero-mira-guardamarmuseografia/>. [7 de abril de 2020].

Salinas de Torrevieja. [En línea]. <http://www.visitasalinasdetorrevieja.com/sitioexcepcional/>. [7 de abril de 2020].

Torrevieja.com. [En línea]. <https://torrevieja.com/centro-de-interpretacion-de-laindustria-salinera/>. [8 de abril de 2020].

(C) Copyright Rafael Martínez García y Revista GeoGraphos, 2020. Este artículo se distribuye bajo una Licencia Creative Commons Reconocimiento-NoComercial 4.0 Internacional.
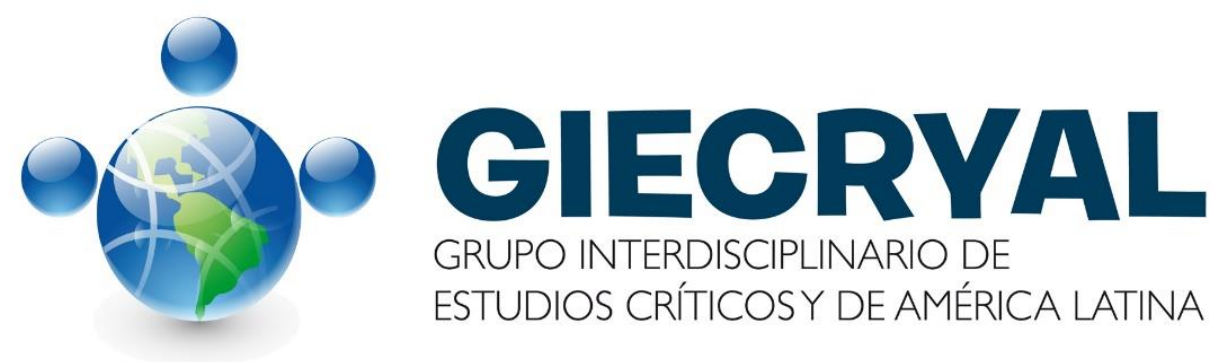